University at Buffalo School of Law

Digital Commons @ University at Buffalo School of Law

Journal Articles

Faculty Scholarship

Fall 2016

\title{
Should the Law Do Anything About Economic Inequality?
}

Matthew Dimick

University at Buffalo School of Law

Follow this and additional works at: https://digitalcommons.law.buffalo.edu/journal_articles

Part of the Tax Law Commons

\section{Recommended Citation}

Matthew Dimick, Should the Law Do Anything About Economic Inequality?, 26 Cornell J.L. \& Pub. Pol'y 1 (2016).

Available at: https://digitalcommons.law.buffalo.edu/journal_articles/81

\section{C) ${ }_{\text {COPYRIGHT }}^{\text {N }}$}

This Article is brought to you for free and open access by the Faculty Scholarship at Digital Commons @ University at Buffalo School of Law. It has been accepted for inclusion in Journal Articles by an authorized administrator of Digital Commons @ University at Buffalo School of Law. For more information, please contact lawscholar@buffalo.edu. 


\title{
ARTICLES
}

\section{SHOULD THE LAW DO ANYTHING ABOUT ECONOMIC INEQUALITY?}

\author{
Matthew Dimick*
}

What should be done about rising income and wealth inequality? Should the design and adoption of legal rules take into account their effects on the distribution of income and wealth? Or should the tax-andtransfer system be the exclusive means to address concerns about inequality? A widely-held view argues for the latter: only the tax system, and not the legal system, should be used to redistribute income. While this proposition comes in a variety of normative arguments and has support across the political spectrum, there is also a well-known law-andeconomics version. This argument, known as the "double-distortion" argument, is simply stated. Legal rules that redistribute income only add to the economic distortions that are already present in the tax system. It would therefore be better for everyone, and especially the poor, to instead adopt an efficient, nonredistributive legal rule, and increase redistribution through the tax system.

This Article challenges the double-distortion argument from a lawand-economics perspective. There are two main arguments, in addition to several other subsidiary points. First, in the abstract, there is no reason to believe that legal rules that have redistributive effects will always reduce efficiency; indeed, they can sometimes increase efficiency. Examples from the regulation of product markets, labor markets, and financial markets underscore this claim. In these cases, legal redistribution is more efficient than redistribution through the tax system. Second, legal rules are likely to be more attractive than taxation precisely in cases where inequality itself or normative concern about inequality is high.

* Associate Professor of Law, SUNY Buffalo Law School, and Visiting Scholar, Department of Political Science, Duke University. Direct Correspondence to: 618 John Lord O’Brian Hall, Buffalo, NY 14260-1100. E-mail: mdimick@ buffalo.edu. For comments, questions, and general encouragement, I wish to thank Matthew Adler, Christine Pedigo Bartholomew, Mark Bartholomew, Anya Bernstein, Guyora Binder, Michael Boucai, Todd Brown, Guido Calabresi, Luis Chiesa, Shi-Ling Hsu, David Engel, Vic Fleischer, Laura Ford, Louis Kaplow, Tara Melish, Tony O'Rourke, Jessica Owley, Brishen Rogers, Matt Steilen, Rick Su, Tico Taussig-Rubbo, and Jim Wooten. Thanks to Rasmus Rosenberg Larsen for helpful research assistance. Also many thanks to the editors at the Cornell Journal of Law and Public Policy. 
Under the optimal tax policy, higher inequality or greater concern about inequality will justify larger tax distortions. Therefore, a particular legal rule is more likely to be more efficient than the optimal tax policy under these circumstances. The ultimate conclusion is that a mix of legal rules and taxation, rather than taxation exclusively, will be the best way to address economic inequality.

InTRODUCTION .................................... 2

I. The Double-Distortion Argument $\ldots \ldots \ldots \ldots \ldots \ldots$. 8

II. Efficient Legal Redistribution................... 12

A. Economic Efficiency........................ 13

B. Redistribution and Inequality ................. 16

C. Examples .............................. 20

1. Product Markets ...................... 21

2. Labor Markets ...................... 23

a. Collective Bargaining ................ 24

b. Minimum Wage Legislation ............. 26

3. Financial Markets ...................... 30

D. Efficient Legal Redistribution ................. 33

III. Optimal Legal Redistribution................... 36

A. Social Welfare ........................... 37

B. Optimal Tax Policy ......................... 39

C. Distributional Judgments .................... 41

D. Level of Inequality ......................... 42

IV. Counterarguments ............................ 43

A. On the Exclusivity of Efficiency ................ 44

B. On the Pareto Frontier: Transaction Costs and the

Coase Theorem ........................... 50

C. Non-Convexities........................... 53

D. Efficient Tax-and-Transfer Policies.............. 54

E. Legal Rules and Corrective Taxation ............. 56

V. Distribution Policy in a Second-Best World ........ 58

A. The Fundamental Theorems of Welfare Economics... 58

B. The General Theory of the Second Best ........... 60

Conclusion........................................ 63

\section{INTRODUCTION}

To the question in this Article's title, a widely-accepted answer within law-and-economics scholarship is, "No."1 Instead of the legal sys-

1 See generally Louis Kaplow \& Steven Shavell, Why the Legal System is Less Efficient than the Income Tax in Redistributing Income, 23 J. Legal Stud. 667 (1994). On the influence of this position, see Ronen Avraham et al., Revisiting the Roles of Legal Rules and Tax Rules in Income Redistribution: A Response to Kaplow \& Shavell, 89 Iowa L. Rev. 1125, 
tem, only the tax system should concern itself with the distribution and redistribution of economic rewards. The reasoning is called the "doubledistortion" argument: any legal rule that redistributes income only adds to the economic distortions already present in the tax system. It would therefore be better for everyone, and especially the poor, to instead adopt a more efficient, non-redistributive legal rule, and then increase transfers to the poor or reduce everyone's taxes. Thus, the law should concern itself only with efficiency-making the economic pie larger-and not with distribution-how to divide the pie. ${ }^{2}$ Since the double-distortion argument concludes that the poor could be made better off if this policy advice was followed, it is an argument that everyone concerned about inequality and poverty should seriously consider. Although coming from the law-and-economics tradition, the argument reflects a widespread and deeply held intuition that is shared across both scholarly disciplines and the political spectrum. ${ }^{3}$ The double-distortion argument was originally made in a 1994 article by Louis Kaplow and Steven Shavell, ${ }^{4}$ and has been a subject of continuous and ongoing debate since then. ${ }^{5}$ Recent at-

1127 (2004) ("In the mid-1990s, in what has come to be considered a classic article, Louis Kaplow and Steven Shavell made what seemed to be a decisive argument regarding the use of redistributive legal rules."); Tomer Blumkin \& Yoram Margalioth, On The Limits of Redistributive Taxation: Establishing a Case for Equity-Informed Legal Rules, $25 \mathrm{VA}$. TAx REv. 1, 2 (2005) (stating " $[\mathrm{t}] \mathrm{hat}$ '[r]edistribution is accomplished more efficiently through the income tax system than through the use of legal rules' seems to be the prevailing norm in the law and economics literature ...."); Zachary Liscow, Reducing Inequality on the Cheap: When Legal Rule Design Should Incorporate Equity as Well as Efficiency, 123 YALE L.J. 2478, 2480, 2480 n. 2 (2014) ("What many consider the decisive argument in favor of this position is the idea of 'double distortion' offered by Louis Kaplow and Steven Shavell . . . ."); and Lee Anne Fennell \& Richard H. McAdams, The Distributive Deficit in Law and Economics (Coase-Sandor Working Paper Series in Law and Economics Working Paper No. 713, 2015) (referring to the "now-conventional assumption that tax-and-transfer will always trump other redistributive methods ...").

2 Kaplow \& Shavell, supra note 1, at 667-68 (summarizing this argument in similar fashion). For a nice overview of the argument, see David Weisbach, Should Legal Rules Be Used to Redistribute Income?, 70 U. CHI. L. REv. 439 (2003).

3 The liberal egalitarian political philosopher John Rawls himself wrote, "[O]nce a suitable minimum is provided by transfers, it may be perfectly fair that the rest of total income be settled by the price system. Moreover, this way of dealing with the claims of need would appear to be more effective than trying to regulate income by minimum wage standards, and the like. It is better to assign to each branch only such tasks as are compatible with one another. Since the market is not suited to answer the claims of need, these should be met by a separate arrangement." John RAwls, A THEORY OF Justice 245 (1971). Other left-leaning egalitarians writing outside law and economics have also readily embraced this idea that markets should be "left alone" and that government, through taxes and transfers, should be solely responsible for redistribution. See, e.g., Ann Alstott, Work vs. Freedom: A Liberal Challenge to Employment Subsidies, 108 YALE L.J. 967, 972 (1999) (writing that "unconditional [cash] grants [for the poor] . . . would help open the way for labor market reforms that can expand employment opportunities," such as "eliminat[ing] the minimum wage").

4 Kaplow \& Shavell, supra note 1.

5 It would be impossible to cite all of the research that engages with this article. Some of the better-known attempts to criticize the double-distortion argument from within a law- 
tention to growing income inequality among politicians, the media, and the public at large has only amplified the scholarly interest in their argument. ${ }^{6}$

This Article challenges the double-distortion argument from a lawand-economics perspective. In particular, the Article contends that legal rules should be used to redistribute income, in addition to taxes and transfers. Two main reasons justify this conclusion. ${ }^{7}$ First, there is no a priori reason why a legal rule that redistributes income should always be distortionary-a necessary condition for the double-distortion argument to be true. Indeed, it is easy to devise examples where a change in legal rules will both redistribute income and increase efficiency. More generally, there is nothing inherent in the concept of redistribution that requires such a change to be accompanied by an efficiency loss. Within economics, redistribution is defined simply as a reduction in inequality. Consistent with this definition, it is possible for a redistributive legal change to be either inefficient or efficient-even in the Pareto sense, where no one is worse off and at least someone is better off. ${ }^{8}$ Since a legal change that meets such conditions both reduces inequality and not only is nondistortionary but increases wealth, it is unambiguously superior to redistribution through the tax and transfer system, which is always distortionary. ${ }^{9}$

Second, the Article demonstrates that even inefficient redistributive legal rules can be more efficient than the optimal tax-and-transfer policy,

and-economics framework include Avraham et al., supra note 1; Chris Sanchirico, Taxes Versus Legal Rules as Instruments for Equity: A More Equitable View, 29 J. Legal Stud. 797 (2000) [hereinafter Taxes Versus Legal Rules]; Chris Sanchirico, Deconstructing the New Efficiency Rationale, 86 CoRnell L. Rev. 1003 (2001) [hereinafter Deconstructing]; and Liscow, supra note 1.

6 See Liscow, supra note 1, at 2482 ("[A]s income inequality increasingly becomes part of the political dialogue, finding efficient ways of reducing income inequality may be increasingly important.").

7 Kaplow \& Shavell, supra note 1, at 667. ("For purposes of this article, the term "legal rules' refers to rules other than those that define the income tax and welfare system."). While certainly the tax system is a species of the legal system, a more substantive distinction might be that legal rules are explicitly intended to regulate behavior, while the purpose of the tax system is to raise revenue for public goods or redistribution. Indeed, when public goods provision or redistribution is the objective, the ideal forms of taxation are those whose effects on behavior are as small as possible. Note that this distinction does not challenge the notion that the tax system could also be used for "non-tax" purposes, for example, to regulate behavior, as with corrective (also called Pigovian) taxation.

8 For instance, any legal rule change that improves the welfare of the poor and leaves the income of everyone else the same will both redistribute income-in the accepted sense of reducing inequality - and be Pareto efficient.

9 That tax and transfers are distortionary is also an assumption of Kaplow and Shavell's that need not be true. In Part IV.D, I relax this assumption and consider efficient tax redistribution. An example of this is transfers that are provided as insurance, which can fill in for missing markets. However, efficient taxation does not disturb the conclusion that both the legal system and the tax system should be used to redistribute income. 
and that this is more likely to be true when inequality is higher. Simply put, if both legal and tax regimes are together doubly distortive, Kaplow and Shavell never furnish a compelling reason for why we should eschew the legal distortion and embrace the tax distortion. A sensible economic analysis would choose the least inefficient option. More importantly, under the typical optimal tax policy, high levels of inequality will justify higher levels of tax distortions. Thus, a given legal rule that accomplishes a certain amount of redistribution and produces a certain level of inefficiency is more likely to dominate the optimal tax policy when inequality is higher. The same conclusion obtains when we hold the level of inequality constant but vary our judgment about it. If the public or policymakers become less tolerant of inequality, larger tax distortions can be justified. But then because of these larger distortions, it is more likely that a particular redistributive legal rule will constitute a more efficient alternative. Thus, redistributive legal rules, even if inefficient, are more likely to be superior to taxes and transfers precisely when inequality is a more serious concern.

A large literature both for and against the double-distortion argument exists, so it is important to clarify the contribution of this Article. As well as I am aware, the claim that redistributive legal rules can increase efficiency has not been made in the double-distortion debate before. ${ }^{10}$ Previous research concedes that legal rules will be distortion-

10 Liscow's Note comes closest to my first point by arguing that redistributive legal rules may entail zero distortion-that is, can be equally efficient to nonredistributive legal rules. Liscow, supra note 1, at 2483-84, 2486-88 (describing the "distribution of legal entitlements that can entail a distortion of neither income nor the activity regulated by the legal rule-a 'zero distortion" "). Outside of his motivating example, however, Liscow appears to concede with the rest of the literature that both legal and tax redistribution will entail some distortion and so the problem is to choose the most efficient-or, perhaps better, the least inefficientpolicy. Id. at 2482-83 (arguing his general point that "using an 'inefficient' legal rule instead of taxation can be an efficient means of redistribution").

That the debate has overlooked the possibility that legal rules can both increase efficiency and reduce inequality is somewhat surprising because it is quite well known among economists and others outside of the double-distortion debate that redistributive policies can also improve efficiency. This conclusion comes mainly from the literature on the economics of information. For an overview, see Karla Hoff, Market Failures and the Distribution of Wealth: A Perspective from the Economics of Information, 24 PoL. \& Soc'y 411, 426 (1998). In a competitive market with perfect information the allocation of resources is generally efficient for any initial distribution of wealth. Id. at 412 . But as several studies have identified, when information is imperfect, efficiency may well depend on the distribution of wealth. See, e.g., Ben Bernanke \& Mark Gertler, Financial Fragility and Economic Performance, 105 Q.J. ECON. 87 (1990) (developing a model of finance where financial instability and agency costs—both inefficient—increase when borrower's net worth is lower); Carl Shapiro \& Joseph Stiglitz, Equilibrium Unemployment as a Worker Discipline Device, 74 Am. Econ. Rev. 433, 439-41 (1984) (demonstrating with an efficiency-wage model of the labor market that a policy intervention can increase efficiency while also lowering profits and increasing wages). As these studies demonstrate, a redistributive policy intervention (including, I would argue, changes in legal rules) can also increase efficiency. This Article agrees with this literature, but 
ary, but argue that inefficient legal rules may still be more efficient than tax-and-transfer policies, similar to the premise of my second point. ${ }^{11}$ Clearly, however, the distinction matters because it strengthens the case for using legal rules to redistribute income. For instance, because of the economic cost, justifying an inefficient legal redistribution will require that there be "significant income differences between plaintiffs and defendants." 12 In contrast, an efficient legal redistribution will always be justified on distributive grounds, even if it reduces income inequality only slightly.

Furthermore, I am aware of no other Article that concludes that the choice of legal rules versus taxes will itself depend on the level of inequality. Previous research has offered a variety of reasons and conditions for when inefficient legal rules will be more efficient than taxes and transfers. ${ }^{13}$ None of these, however, recognize that the choice between law and taxes depends on the level of inequality itself. Since inequality is what we care about when redistributing income, this is a significant point.

Finally, following Kaplow and Shavell, virtually all previous contributions have worked with examples in the area of tort law. ${ }^{14}$ Kaplow and Shavell are absolutely correct to say that their analysis goes beyond this specific case. Nevertheless, this focus has perhaps unnecessarily constrained the debate. For example, elsewhere Kaplow and Shavell argue

also argues that efficient legal redistributions are not limited to the case of imperfect information.

11 To adopt a phrase, one can call my argument the "negative distortion" argument- that is, distortions that are less than zero, or increase efficiency-in contrast with Kaplow and Shavell's double-distortion argument or Liscow's zero-distortion argument.

12 Liscow, supra note 1, at 2484 (emphasis added).

13 See, e.g., Deconstructing, supra note 1 (arguing that income may well be an appropriate signal when designing legal rules to maximize social welfare); Avraham et al., supra note 1 (arguing that when one introduces heterogeneity in individuals' care-taking abilities and additional information restrictions, it may be appropriate to condition legal rules on individuals' income); Blumkin \& Margalioth, supra note 1, at 11-14 (arguing that when administrative and compliance costs are considered, legal rules may be less inefficient than taxes in redistributing income); Liscow, supra note 1, at 2484 (describing six factors when legal rules will less inefficient than taxation: "legal rules are more desirable when: (1) there actually are significant income differences between plaintiffs and defendants; (2) group membership is inelastic; (3) responses to a rule change are slow and the income transfers are fast; (4) the economic incidence of a policy is on the desired individuals; (5) parties can bargain at low cost; and (6) redistributing to the poor is more important than violating notions of horizontal equity."); Fennell \& McAdams, supra note 1, at 1 (arguing that "[i]n contexts where political impediments to tax-based redistribution exceed the impediments to doctrinal redistribution, it may be possible to increase welfare by redistributing outside of tax").

14 See, e.g., Deconstructing, supra note 1, at 1008 (considering an income-dependent damages rule, as in Kaplow and Shavell's double-distortion argument); Avraham et al., supra note 1 , at 1127 (focusing on an income-dependent damage rule in torts, as in the doubledistortion argument); Liscow, supra note 1, at 2486 (comparing negligence and strict liability rules). 
that "many legal rules probably have little effect on the distribution of income," because litigants will have similar incomes or be on each side of a transaction equally often. ${ }^{15}$ While this is more likely to be true in areas of tort or contract law, for instance, the scope for redistributive law is much greater beyond these areas. The Article produces several examples-from the areas of product markets, labor markets, and capital markets-to establish this claim.

The organization of the Article proceeds as follows. Part I recapitulates the Kaplow and Shavell double-distortion argument. After defining both efficiency and redistribution, Part II produces several examples from product markets, labor markets, and capital markets to demonstrate cases where legal interventions can both reduce inequality and increase efficiency. From this, I then make the more general argument that redistributive legal rules have no a priori relationship to efficiency. At the most general level, a reduction in inequality can be associated with a change in total wealth that makes at least someone worse off and no one better off (inefficient), makes at least one person better off and another worse off while reducing total wealth (inefficient), makes one person better off and another worse off while increasing total wealth (KaldorHicks efficient), or makes at least someone better off and no one worse off (Pareto efficient).

In Part III, I consider cases where a legal redistribution reduces efficiency but may still be more desirable than tax-and-transfer redistribution. While a legal redistribution may introduce some inefficiency, if the loss is smaller than that caused under the optimal tax-and-transfer policy, then the legal redistribution will be preferred. Introducing the discussion of the optimal tax policy requires a discussion of an additional criterion for normative economic analysis, the idea of social-welfare maximization. As the name suggests, the optimal tax policy maximizes welfare, rather than wealth, as in the efficiency criteria. These two objectives may well conflict, which justifies the efficiency loss under the optimal tax policy. But if welfare maximization is the goal, there may be an inefficient legal redistribution that dominates the optimal tax policy in welfare terms. Hence, I title this Part optimal, rather than efficient, legal redistribution.

Part IV considers a series of objections one could make to my argument. One could argue that there is no disagreement with Kaplow and Shavell in the sense that efficiency remains the exclusive criterion of legal evaluation in the case of efficiency legal redistribution. My response is that there is no particularly good reason to privilege the efficient, rather than the redistributive, quality of such rule changes. To the

15 Louis Kaplow \& Steven Shavell, Fairness Versus Welfare 33 (2009). 
contrary, there is compelling justification for giving the redistributive aspect equal consideration through a welfare argument. One could also object that if the non-redistributive legal rule in question is Pareto efficient then Kaplow and Shavell's assumption that legal redistribution will always be inefficient is sound. But this requires the unjustified assumption that the rule is uniquely Pareto efficient. Indeed, if there is more than one Pareto efficient legal rule, the only criterion by which to evaluate legal rules is by their effect on distribution. This Part also discusses implications for the argument of "non-convexities" in the economy, efficient tax-and-transfer policies, and the choice between what is called "corrective taxation" and legal rules.

Part V ties together the analysis with a broader consideration about distributive economic policy in a world of imperfect markets. One can read Kaplow and Shavell's contribution as a way to make relevant for policy the insight of what is called the second fundamental theorem of welfare economics. That theorem says that with perfectly competitive markets any possible Pareto-efficient equilibrium can be achieved with lump sum taxation. Similar to Kaplow and Shavell's argument, the implication is that policy makers need not "disturb" the workings of the market in order to get to a Pareto-efficient equilibrium with a more desirable distribution of income. Unfortunately, implementing this program requires the implausible condition that governments have perfect information about consumers' tastes and firms' production possibilities. In a world without perfect information, any government system of taxation will be distortionary. Kaplow and Shavell's argument is then that, given the distortionary nature of taxation, it is best not to add to the distortions with redistributive and distortionary legal rules. My response is that the problem of imperfect markets does not apply only to the tax system, and to the extent that there is market failure in other aspects of the economy, remedying some of these failures may increase both inequality and inefficiency. As long as this is true, there is always scope for legal intervention for distributive as well as efficiency reasons.

\section{The Double-Distortion Argument}

This Part presents an overview of Kaplow and Shavell's argument for why the legal system is less efficient than the income tax system for redistributing income. The argument is simple and compelling. Their basic claim is that "using legal rules to redistribute income distorts work incentives fully as much as the income tax system . . . and also creates inefficiencies in the activities regulated by the legal rules." 16 Consequently, "redistribution through legal rules offers no advantage over re- 
distribution through the income tax system and typically is less efficient." 17 From this analysis they also draw the more general conclusion that "it is appropriate for economic analysis of legal rules to focus on efficiency and to ignore the distribution of income in offering normative judgments." 18

To understand Kaplow and Shavell's argument, it will be helpful to use their own illustrative example. They use an example from tort law, but it is easy to see that it has more general applicability. ${ }^{19}$ Individuals engage in two kinds of activities. They work, or supply labor, which is costly either because effort is costly or because time spent working takes time away from leisure. Individuals also take precautions against the likelihood of causing accidents, which is also costly, in terms of time or money. ${ }^{20}$

They consider two different legal rules in tort, beginning with an efficient one. This is the strict liability rule. Under this rule, a defendant is liable for the harm she causes. As is well understood, a strict liability rule leads to the efficient level of care. ${ }^{21}$ This is because when a person pays for the damage she causes, she is forced to fully "internalize" the costs of her behavior. For concreteness, suppose that each person's expected net accident costs under strict liability are $\$ 1,000 .^{22}$

Now compare the efficient, strict-liability rule, with an inefficient legal rule. The proposed inefficient legal rule is one where the damages a person must pay for harm-causing behavior vary by income. ${ }^{23}$ For example, suppose a poor person, with income of $\$ 0$, must pay $\$ 500$ (or half) of the expected net accident costs, while a rich person, with an income of $\$ 100,000$, must pay $\$ 2,000$ (or double the costs). ${ }^{24}$ This rule is inefficient because it induces the poor to take too little care and the rich to take too much than is efficient. ${ }^{25}$ However, the rule is also redistributive, since it reduces the expected costs the poor have to pay for harm-causing behavior, while increasing the expected costs of the rich. If we include these expected accident costs into each person's expected income, for exam-

17 Id. at 667.

18 Id. at 677.

19 Id. at 669 ("For concreteness, we will use a specific example in our analysis, but it will be clear that our argument does not depend on the particulars of the example.").

$20 \mathrm{Id}$.

21 Id. ("It is a familiar result that the strict liability rule- - under which individuals pay for the harm they cause-leads to efficient behavior.").

$22 I d$.

23 Id. ("Redistribution might be accomplished, for example, by setting damages higher when the injurer is wealthy and lower when the injurer is poor.").

$24 I d$.

$25 I d$. ("Such a redistributive legal rule would be inefficient: it would induce the wealthy to take more care and the poor to take less care than is efficient."). 
ple, expected inequality is lower under the inefficient, but redistributive, legal rule. ${ }^{26}$

Added to the tort system-or more generally the legal system-is the tax system. Kaplow and Shavell consider a case where people pay a $20 \%$ tax rate on income above $\$ 10,000$, while those below this threshold receive transfer payments equaling $20 \%$ of the difference between their income and the threshold. ${ }^{27}$ Thus the rich person would pay $\$ 18,000$ in taxes, while the poor person would receive $\$ 2,000$ in transfer payments. $^{28}$

Next, add together both the tax system and the expected accident costs of the inefficient legal rule. It is this combination that determines individual work incentives and ultimately welfare. ${ }^{29}$ The rich person's total expected costs are $\$ 20,000$, while the poor person expects to receive (or "pays" a negative tax in amount) $\$ 1,500 .{ }^{30}$ Essentially, these sums of tax and liability costs define the total marginal tax rates of both the legal and tax systems. A critical observation is that because both the amount of taxes paid and the liability costs vary by income, they both reduce the incentives to work. ${ }^{31}$

The next step is to compare this regime, with the inefficient legal rule, to a regime with the efficient legal rule and a more redistributive tax system. Kaplow and Shavell do this in two steps. First, they construct a new, more redistributive income tax schedule. ${ }^{32}$ In this new tax schedule, the rich person pays $\$ 19,000$ (rather than $\$ 18,000$ ) in taxes, while the poor person receives $\$ 2,500$ (rather than $\$ 2,000$ ) in transfer payments. ${ }^{33}$ Second, they calculate total tax and accident costs under the new tax schedule and the efficient legal rule. Since the expected costs are $\$ 1,000$ for everyone, this yields a total tax and accident cost of $\$ 20,000$ for the rich and $\$ 1,500$ for the poor. ${ }^{34}$

Not surprisingly, since the new tax schedule was chosen precisely to produce this result, the total tax and liability costs are identical for each person under both the old and the new regimes. Labor supply incentives

$26 I d$. ("Expected accident costs must be a function of income if the rule is to redistribute income relative to a rule under which everyone's accident costs are the same.").

27 Id. at 670.

28 That is, the rich pay $0.20 \times(\$ 100,000-\$ 10,000)$ in taxes, while the poor receive 0.20 $\mathrm{x}(\$ 10,000-\$ 0)$ in transfer payments.

$29 I d$. at 670 ("It is this combination that determines an individual's welfare level and work incentives.").

30 Id. at 671 fig. 2.

$31 \mathrm{Id}$. at 671 ("[W]e emphasize that when an individual with income $y$ contemplates earning additional income by working harder, his total marginal expected payments equal the sum of his marginal tax payment and the expected marginal cost on account of accidents.").

$32 \mathrm{Id}$. at $671-72$.

33 Id. at 673 fig. 4.

$34 \mathrm{Id}$. at 672 fig. 3. 
are therefore identical between the two regimes, because the marginal costs are the same. ${ }^{35}$ This is a device to make clear the logical inference that follows. Since labor incentives are the same, total tax revenue, as well as total economic output, must be higher under the second regime. ${ }^{36}$ Tax revenues are higher, because with identical labor incentives, the new tax schedule, with higher rates on the rich, collects more revenue. ${ }^{37}$ Indeed, if our simple example is a society consisting of only these two individuals, the additional revenue is $\$ 500$. The rich person pays $\$ 1,000$ more in taxes, while the poor person receives an additional $\$ 500$ in transfer payments. Total economic output is higher, because under the efficient legal rule, both the rich and the poor choose the efficient level of care. In fact, tax revenues increase precisely by the amount of deadweight loss caused under the inefficient legal rule. ${ }^{38}$ This additional revenue can then be used to make society better off-either by lowering taxes, increasing transfers to the poor, or spending the revenue on public goods that benefit everyone. ${ }^{39}$

Thus, using the legal system for redistributive objects leads to a "double distortion" in economic behavior. The tax system is already redistributive and distortionary. Using the legal system for redistributive purposes only adds to these distortions. It would be preferable, in Kaplow and Shavell's reasoning, to make the economic system and its governing legal rules as productive as possible and to use the increased output for further redistribution through the tax system. Even keeping tax rates constant, the additional output under an efficient legal regime will increase tax revenue, making it possible to increase transfer payments to the poor, reduce taxes, or both. This achieves more redistribution and makes everyone better off. Even those more interested in redistribution than efficiency and not inclined to find interest in a law-and-economic analysis should take heed. Increasing efficiency can enhance redistributive objectives. A larger pie makes it possible to increase the welfare of the poor.

$35 I d$. at 673 ("[E]ach individual . . . will choose to earn the same income under each regime because his incentives will be unchanged: a marginal dollar earned will result in the same incremental costs (taxes plus accident costs) under both regimes.").

$36 I d$. ("Although work effort and an individual's after-tax welfare are identical under the two regimes, the state collects more tax revenue in the new regime because it involves a more efficient legal rule.").

37 Id.

$38 I d$. ("[T]he new tax collects all the resources saved by the efficient legal rule.").

39 Id. at 674 ("With this additional revenue, the government can make each individual better off-for example, by lowering taxes (for the poor, increasing transfers) by a fixed amount for each individual or spending the funds on a public good that benefits everyone."). 


\section{Efficient Legal Redistribution}

A critical element in Kaplow and Shavell's argument is that legal rules that redistribute income are always inefficient. For example, they write, "[U]sing legal rules to redistribute income distorts work incentives fully as much as the income tax system-because the distortion is caused by the redistribution itself-and also creates inefficiencies in the activities regulated by the legal rules." 40 If legal rules that redistribute income do not also create inefficiencies, there is no double-distortion.

The first claim of this Article is that their conclusion that legal rules are distortionary does not in general follow from the premise that they are redistributive. That is, not all legal rules that redistribute income are inefficient, and indeed some can be efficient—even possibly Pareto efficient. In fact, there is nothing in the concept of redistribution, properly understood, that implies either more or less efficiency in economic activity. It follows from this that if a legal rule both redistributes income and increases efficiency, it will be strictly superior to redistribution through the tax-and-transfer system. While taxation is always distortionary (as understood by Kaplow and Shavell), ${ }^{41}$ and therefore always reduces wealth, some legal redistributions can increase wealth.

To make this argument concrete, I first begin by defining both efficiency and redistribution as those terms are used by economists. With the definition of redistribution, it is possible to talk about the concept of a legal redistribution. Since this concept builds on the more general idea of redistribution within economics, it is no different from the way redistribution through taxes and transfers is understood. The definition is therefore fully general and does not depend on any special assumption about how redistribution through legal rules specifically takes place.

With these definitions in hand, I then make this Part's first point by providing a series of examples. Examples from legal rules governing product markets, labor markets, and capital markets all underscore the point that market inefficiencies can also increase inequality. In such cases, legal rules can both increase efficiency and reduce inequality.

Following these examples, I make the argument more abstract, showing how redistribution relates-or, more accurately, does not relate-to efficiency in a general setting. A legal rule that has a redistributive effect can make everyone better off, and therefore be Pareto efficient, or it can make everyone worse off, in which case it is inefficient for violating the Pareto principle. Even more, a redistributive legal rule can make one person better off and another worse off and there is still no obvious consequence for efficiency. If the "winner" could com-

40 Id. at 667-68.

41 For a discussion of an exception to this assumption, see infra Part IV.D. 
pensate the "loser," the legal redistribution will be Kaldor-Hicks efficient. If not, the rule will be inefficient. There is therefore nothing about redistribution that necessarily increases or-more appositely—decreases wealth.

\section{A. Economic Efficiency}

Are legal redistributions necessarily inefficient? To answer this question, we need to be clear about what is meant by the concept of efficiency. This section therefore quickly reviews the definitions of efficiency found in the economics and law-and-economics literatures.

Most simply, efficiency is the idea of wealth maximization-as distinct from welfare maximization, an idea that we will encounter later. ${ }^{42}$ The two best-known definitions of efficiency are Pareto efficiency and Kaldor-Hicks efficiency. ${ }^{43}$ Beginning with the concept of Pareto efficiency, this idea is typically divided into two subconcepts. ${ }^{44}$ They are closely related, but their distinction is important. The first idea is Pareto superiority. This idea says that one allocation of income (for example) is Pareto superior to another if it makes no one worse off and at least one person better off. ${ }^{45}$ In other words, there is at least some improvement in total social welfare. Hence a change in allocation that is Pareto superior to another is also called a Pareto improvement. ${ }^{46}$ Similarly, but conversely, we can say that one allocation is Pareto inferior if it makes at least one person worse off even if it makes others better off. ${ }^{47}$

42 There are several introductions to the idea of economic efficiency. For an excellent introduction for the law-and-economics reader, see generally Jules L. Coleman, Efficiency, Utility, and Wealth Maximization, 8 Hofstra L. Rev. 509 (1980) (introducing the ideas of Pareto efficiency and Kaldor-Hicks efficiency).

$43 I d$. at 512-14. Strictly speaking, we should reserve the term "wealth maximization" for the criterion of Kaldor-Hicks efficiency. See Richard A. Posner, Economic Analysis of LAw 14 (1998) [hereinafter Posner, ECONOMIC ANALYsis] (equating wealth maximization with Kaldor-Hicks efficiency); Richard A. Posner, The Ethical and Political Basis of the Efficiency Norm in Common Law Adjudication, 8 Hofstra L. Rev. 487, 491 (1980) [hereinafter Posner, Ethical and Political Basis] (equating wealth maximization with Kaldor-Hicks efficiency).

44 Coleman, supra note 42, at 512-13 (distinguishing between Pareto superiority and Pareto optimality (or, as termed here, Pareto efficiency)).

$45 I d$. at 513 ("An allocation of resources is Pareto superior to an alternative allocation if and only if no is made worse off by the distribution and the welfare of at least one person is improved.").

46 Joseph E. Stiglitz, Economics of the Public Sector 93 (2d ed. 1988) (referring to changes that make some better off without making anyone worse off as "Pareto improvements").

47 Although Pareto superiority is stated in terms of utility or welfare ("worse off," "better off," etc.), one can construe it as a principle of wealth maximization. Part of the appeal of the Pareto principle is that it does not rely on interpersonal comparisons of utility. On the problem of interpersonal comparisons of utility, see infra notes 202-34 [Part IV.A] and accompanying discussion. Thus the only way to demonstrate that a change is Pareto superior is to show that everyone consented to it. One way to do this is by using the willingness-to-pay principle. As 
In addition to the concept of Pareto superiority is the idea of Pareto efficiency. An allocation is Pareto efficient if no one can be made better off without also making someone else worse off. ${ }^{48}$ Thus, when an allocation is Pareto efficient, we have exhausted all the Pareto superior, or Pareto improving possibilities-it is no longer possible to make all persons or at least one person better off. ${ }^{49}$ Despite this limit to Pareto improvements there may be many-perhaps infinite-Pareto efficient allocations. Because of these many possibilities it is said that the collection of all Pareto efficient allocations constitutes the "Pareto frontier."50

One reason that Pareto superiority has such a strong attraction is that it is underlined by unanimity: a change can improve efficiency only so long as no one is made worse off. ${ }^{51}$ But, since economic and policy changes frequently do make somebody worse off, the conditions for Pareto superiority are rarely satisfied.52 For this reason, the concept of Kaldor-Hicks efficiency is frequently called upon. ${ }^{53}$ An allocation is said to be Kaldor-Hicks efficient relative to another if the "winners" could compensate the "losers." 54 Note that this compensation is typically thought of as merely hypothetical. If compensation did actually occur,

Judge Posner explains, "If $A$ sells a tomato to $B$ for $\$ 2$ and no one else is affected by the transaction, we can be sure that the utility to $A$ of $\$ 2$ is greater than the utility of the tomato to $A$, and vice versa for $B$, even though we do not know how much $A$ 's and $B$ 's utility has been increased by the transaction." Posner, Ethical and Political Basis, supra note 43, at 489. Thus, willingness to pay, a measure of wealth, becomes the main criterion to determine whether a change is Pareto superior.

48 Coleman, supra, note 42, at 512-13. Coleman refers to this condition as Pareto optimal or a Pareto optimum. In order to keep distinct the ideas of wealth and welfare maximization, I will typically use efficient or efficiency for the former and optimum or optimal for the latter. Hence, I refer to the Pareto conditions as Pareto efficient or Pareto efficiency.

$49 \mathrm{Id}$. at 513 (noting that Pareto efficiency and Pareto superiority "are analytically related in that a Pareto-[efficient] distribution has no distributions Pareto superior to it").

50 Jean Hindriks \& Gareth D. Myles, Intermediate Public Economics 425 (2006).

51 Coleman, supra note 42, at 546 n. 61 ("Nicholas Kaldor (of the Kaldor-Hicks test) early on conceived of the Pareto-superior test as rooted in the principle of consent."); see also Posner, Ethical and Political Basis, supra note 43, at 488 ("[W]ealth maximization, especially in the common law setting, derives support from the principle of consent that can also be regarded as underlying the otherwise quite different approach of Pareto ethics.").

52 Posner, Economic Analysis, supra note 43, at 14 (explaining that Pareto superiority "has few applications to the real world because most transactions . . . have effects on third parties, if only by changing the prices of other goods ..."). To put the shortcoming more sharply, some alternatives are incomparable under the Pareto-superiority criterion. HINDRIKS \& Myles, supra note 50, at 439 ("Another failing of the Pareto preference is that it is not always able to compare alternative states. In formal terms, it does not provide a complete ordering of states.") (emphasis in original). In addition to this shortcoming, Pareto superiority is indifferent to distributive judgments. Id. at 438. I further explore these shortcomings later in the article. See infra Part IV.A.

53 Posner, Economic Analysis, supra note 43, at 14.

54 Coleman, supra note 42, at 513 ("One state of affairs ( $E$ ') is Kaldor-Hicks efficient to another $(E)$ if and only if those whose welfare increases in the move from $E$ to $E$ ' could fully compensate those whose welfare diminishes with a net gain in welfare."). 
the change in allocation would be Pareto efficient as well. ${ }^{55}$ Nevertheless, if it is at least feasible for winners to compensate losers, then it must be true that total wealth in society has increased. ${ }^{56} \mathrm{We}$ can then say that new allocation is more efficient than the old. Because of this greater flexibility, Kaldor-Hicks efficiency is typically the criterion of choice when law-and-economics scholars write about efficiency. ${ }^{57}$

These ideas can be illustrated in the following Figure 1. Each axis of Figure 1 measures the utility $(U)$ of two people, person 1 on the horizontal axis and person 2 on the vertical axis. In addition, let $y$ represent a person's income. Therefore, each person's income is labeled $y_{1}$ and $y_{2}$. Each person then gets a certain level of utility from the income they have, and utility is increasing in income. That is, $U_{l}=U\left(y_{1}\right)$.

Income, and therefore utility, increases as one moves further from the origin on either axis. The curved line represents the utility possibility frontier. ${ }^{58}$ The utility possibility frontier represents the maximum amount of utility that one individual can attain given the utility of another. ${ }^{59}$ The utility possibility frontier is also the Pareto frontier. ${ }^{60}$ Thus, this line represents the set of Pareto efficient allocations-along the line, for example, the utility of person 1 can only be increased at the expense of person 2. Legal regimes $A$ and $B$ are both Pareto efficient, for example, and moving between them requires making either person 1 or 2 better or worse off. However, within the Pareto frontier, improvements that make no one worse off are possible. Legal regime $A$, for instance, represents a Pareto improvement from regime $C$, and makes both 1 and 2 better off.

Also observe that the dashed line along the 45-degree angle represents allocations that give persons 1 and 2 equal income and utility. Observe that points $A$ and $B$ are both Pareto efficient. Despite that, point $A$ exhibits greater inequality than point $B$. Thus, Pareto efficiency is indifferent between these two allocations. Despite the substantial difference between them in the level of inequality, Pareto efficiency cannot make any distributional judgment. ${ }^{61}$ Notice also that Pareto efficiency cannot

55 Id. ("Under Kaldor-Hicks, compensation to losers is not in fact paid. Were the payment transaction costless and full compensation given to the losers, Kaldor-Hicks distributions would be transformed into Pareto-superior ones.").

56 Because compensation implies the common metric of willingness to pay, it becomes clear why efficiency is concerned with wealth maximization, rather than welfare maximization.

57 Posner, Economic Analysis, supra note 43, at 15 ("When an economist says that free trade or competition or the control of pollution or some other policy or state of the world is efficient, nine times out of ten he means Kaldor-Hicks efficient.”).

58 For further discussion and theoretical grounding for the utility possibilities frontier, see $i d$. at $424-25$.

59 Stiglitz, supra note 46 , at 63-64.

$60 \mathrm{Id}$.

61 The indifference limitation of Pareto efficiency was mentioned previously, supra note 52. I discuss this shortcoming further below, infra note 205 and accompanying text. 
make any judgment about whether point $B$ or point $C$ is better than the other. Although point $B$ is Pareto efficient, and point $C$ is not, moving from point $C$ to point $B$ is not a Pareto improvement, since it requires making person 1 worse off. Points $B$ and $C$ are therefore incomparable under the Pareto efficiency concept. ${ }^{62}$ However, since a move from $C$ to $B$ makes it possible for person 2 to compensate person 1, Kaldor-Hicks efficiency ranks $B$ as superior to $C .^{63}$

\section{B. Redistribution and Inequality}

To answer the question of whether legal redistributions are necessarily inefficient, we also need to define the concept of redistribution. It is not clear how the double-distortion debate defines redistribution. To begin, Kaplow and Shavell are correct to insist that the kinds of legal rules they have in mind are not limited to those that make damages a function of the parties' income. ${ }^{64}$ They do, however, appear to construe redistribution in a way that is at least functionally equivalent to the tax-andtransfer system: as cash transfers from rich to poor. ${ }^{65}$ Other contributions to this debate also appear to adopt this interpretation of redistribution, which suggests that this may indeed be the way that Kaplow and Shavell think about it. ${ }^{66}$

62 Note that incomparability is not the same as indifference. To say that Pareto superiority is indifferent between two different states means that they are ranked equally "good." In contrast, incomparability means that the two states cannot be ranked at all. See HindriKs \& MYLES, supra note 50, at 439.

63 Kaldor-Hicks efficiency therefore addresses the incomparability problem of Pareto superiority. As I will discuss further below, however, it does not solve the indifference problem. See infra Part IV.A.

64 Sanchirico claimed that Kaplow and Shavell's argument holds "only when damages are made a function of the parties' incomes." Sanchirico, supra note 5, at 799. However, Kaplow and Shavell quite clearly — and convincingly, in my view—contend that this assertion is incorrect. See Kaplow \& Shavell, supra note 1, at 679 ("It should be apparent that our result does not depend on the nature of the activity (for example, one could incorporate victim care), the form of the legal rule, the income tax system, or the distribution of ability.").

65 To obtain identical results in Kaplow and Shavell's argument, one need not only consider damage rules. More generally, however, the effect they describe would need to function equivalently to a tax on the relevant behavior. See Liscow, supra note 1, at 2489 ("Kaplow and Shavell's important insight is that requiring defendants to pay higher damages if they are rich is equivalent to an income tax."); $i d$. at 2490 (referring to the type of legal rules that Kaplow and Shavell have in mind as a "Kaplow-Shavell-type tax").

66 Id. at 2487 (explaining with his example that a reduction in inequality that follows a change in liability rules "is perhaps better defined as distribution rather than redistributionindeed, perfect, costless, equity-informed distribution") (emphasis in original). Note that Liscow's example still involves redistribution through cash "transfers" - cash payments made to compensate for all harm caused under a strict liability rule. The examples below demonstrate that cash transfers need not be required to speak intelligibly about the distributional effects of legal rules. Furthermore, as the discussion below illustrates, there is no meaningful distinction between distribution and redistribution in economic theory. 
However, there is nothing special about cash transfers in the idea of redistribution. Within economics, redistribution is understood simply as a reduction in income or wealth inequality. ${ }^{67}$ The definition seems straightforward enough, but we now must be clearer about the concept of inequality more specifically. In this Article, I will use the idea of Lorenz dominance to compare economic allocations according to corresponding levels of inequality. ${ }^{68}$ The concept of Lorenz dominance comes from the well-known tool of the Lorenz curve to measure inequality. ${ }^{69}$ To construct a Lorenz curve, one must first order individuals in terms of increasing levels of income (or wealth). ${ }^{70}$ The Lorenz curve then measures the proportion of total income owned by a given proportion of the population. ${ }^{71}$ Inequality will be present (and in the real world, it always is) whenever a certain percentage of the population (less than 100\%) holds less than that same percentage of the income. ${ }^{72}$

Using the definition of the Lorenz curve we can compare two different income distributions. ${ }^{73}$ Distribution $A$ will Lorenz dominate distribution $B$ if any given percentage of the population under $A$ always holds a larger percentage of the income than under $B .^{74}$ Thus Lorenz dominance between distributions will occur when the poorer fraction of the population holds more of the income in one than in the other.

Figure 3 represents the idea of using Lorenz curves to rank income distributions. The horizontal axis represents the proportion of the population, arranged in order of increasing income, while the vertical axis represents the proportion of income (or wealth). If a society enjoyed perfect equality, each person would own an equal fraction of income, and the proportion of the population would always equal the proportion of in-

67 Peter Lambert, The Distribution and Redistribution of Income 37-39 (3d ed. 2001) (defining redistribution in terms of a policy—in this case, taxation-that "exerts an equalizing effect on the distribution of income").

68 For an introduction to the notion of Lorenz curves and Lorenz dominance, see HINDRIKS \& MYLES, supra note 50, at 471-72. For a more in-depth treatment, see LAMBERT, supra note 67 , at $30-37,44-49$.

69 HindRIKS \& MYles, supra note 50, at 471.

70 Id. ("The Lorenz curve is constructed by arranging the population in order of increasing income and then graphing the proportion of income going to each proportion of the population.").

$71 \mathrm{Id}$.

72 Id. ("If there is any degree of inequality, the ordering in which the households are taken ensures that the Lorenz curve lies below the diagonal since, for example, the poorest half of the population must have less than half the total income.").

73 Id. ("The Lorenz curve can be employed to unambiguously rank some income distributions with respect to income inequality.").

$74 I d$. at 471-72 (providing an example of how income distributions can be ranked using Lorenz curves); see also LAMBERT, supra note 67, at 26-27 (explaining that a distribution A Lorenz dominates a distribution B when the "bottom $100 p$ per cent of income units in distribution A have a greater share in total income than do the corresponding group in distribution B, and this is true for every $p$ between 0 and 1 ”). 
come. This condition is represented by the dashed, "line of equality." However, in no society is the income distribution ever perfectly equal, and so the Lorenz curve will always be convex, with a given proportion of the population possessing less than an equal proportion of the income. The three different curves, $A, B$, and $C$, represent different distributions of income. In the figure, distribution $B$ Lorenz dominates distribution $C$ because $B$ lies everywhere above $C$. Intuitively, income is distributed more equally, since any (poorer) proportion of the population below the richest person holds a greater share of the income in $B$ than in $C$. In contrast, note that we cannot rank distribution $A$ with either $B$ or $C$. The reason is that the curve representing distribution $A$ crosses both $B$ and $C$. At some proportion of the population, the poorer fraction of $A$ owns more but then also less than $B$ or $C .^{75}$

75 Thus the idea of Lorenz dominance has both strengths and weaknesses. The main strength is that when Lorenz dominance occurs, it allows a unanimous ranking of income distributions. See id. at 49 ("Lorenz dominance carries with it welfare approval according to every strictly increasing and concave utility-of-income function ... ") (emphasis added). There are many different measures of inequality. And depending on the kind of change in the income distribution, one index might conclude that inequality has fallen, while another might reach the opposite conclusion. But if one distribution Lorenz dominates another, all indexes will agree on whether inequality has increased or decreased.

On the other hand, as was show in the comparison of distributions $A$ with $B$ and $C$ in Figure 3, Lorenz dominance does not supply an answer to this question in all cases. An income distribution can change without Lorenz dominance occurring. This can happen, for example, when the poor receive a lower share of the income but the lower middle class gains a larger share, both relative to the rich. In this case, the Lorenz curve of the second distribution may not lie everywhere above the curve of the first. In this case, the Lorenz curves cross, and it is not possible to say whether one distribution dominates the other. LAMBERT, supra note 67, at 27. Thus, similar to Pareto efficiency, see infra note 62 and accompanying text, Lorenz dominance does not give us a complete ordering, which makes some distributions incomparable.

This does appear to be a real world problem as well, and can arise when trying to compare inequality across different countries. LAMBERT, supra note 67, at 27 (reporting that one study "found Lorenz crossings in more than 30 per cent of 2,556 possible pairwise comparisons between 72 countries"). This is a major reason why alternative measures of income distribution, such as the Gini coefficient, have been proposed. The Gini coefficient measures the area between the Lorenz curve and the line of equality. See Hindriks \& Myles, supra note 50, at 472-74. Unlike Lorenz dominance, the Gini coefficient supplies a complete ordering of distributions. Id. at 474 ("This definition makes clear that the Gini . . . can be used to rank distributions when the Lorenz curves cross, since the relevant area is always well defined."). That is, with the Gini coefficient we will always be able to say whether inequality is larger or smaller.

The drawback, as already implied, is that these alternative inequality indices do not always agree. For example, some argue that the Gini coefficient does not give enough weight to income changes at the top (or bottom), and so that the Gini coefficient gives an understated picture of the recent rise in inequality in the United States, where income gains have been concentrated at the very top of the distribution. See, e.g., Anthony B. Atkinson et al., Top Incomes in the Long Run of History, 49 J. Econ. Liт. 3, 10 (2011) ("The most commonly used summary measure of overall inequality, the Gini coefficient, is more sensitive to transfers at the center of the distribution than at the tails.").

Despite these drawbacks, none of them presents any serious obstacle to the argument made in this Article. There may well be a debate about whether a change in legal rules will 
Thus, comparing distributions of income allows us to speak precisely about redistribution, in the way we have already defined it. ${ }^{76}$ For instance, if some policy $x$ changes the income distribution from $C$ to $B$, then we can say that policy $x$ is redistributive. Note that this is a general definition of redistribution. In fact, a special case of this definition corresponds exactly to the way economists measure the redistributive effects of taxation. ${ }^{77}$ The redistributive effect of taxation is also defined in terms of Lorenz curves and Lorenz dominance. ${ }^{78}$ And a standard result in public economics demonstrates that a progressive tax schedule-as contrasted with a proportional or regressive one-will be redistributive in precisely this sense. ${ }^{79}$ Thus, a tax-and-transfer policy will be redistributive when the Lorenz curve of disposable income (i.e., after taxes and transfers) dominates the Lorenz curve of market inequality (i.e., before taxes and transfers)..$^{80}$

We can understand the distributive effects of legal rules in exactly the same way. Thus, for instance, we can define a legal redistribution as one where the distribution of income caused by the legal rule Lorenz dominates the distribution of income prior to the enactment or application of the legal rule.

For an illustration of this, we can use again the example provided in Kaplow and Shavell's argument. Kaplow and Shavell's example of a redistributive legal rule-damage awards that depend on income-conforms exactly with this general definition of redistribution. Compared to a legal rule that gives both poor and rich individuals identical accident costs, the legal rule that allows damages to vary by income is redistributive precisely because it reduces inequality. Since the poor's expected accident costs decrease from $\$ 1,000$ to $\$ 500$, the expected income of the

increase or decrease inequality according to one or another inequality index. But this problem exists independently of the question of whether the legal system should be used to redistribute income. In order to focus on the debate that matters for this Article, I assume that all distributional changes can be ranked according to the Lorenz dominance criterion. Since Lorenz dominance implies unanimous agreement, what this means essentially is that we only consider distributional changes on which all inequality indices would agree.

76 See supra note 67 and accompanying text.

77 LAMBeRT, supra note 67, at 37-39 (defining redistribution in terms of the equalizing effect of progressive taxation).

78 See, e.g., Ulf Jakobsson, On the Measurement of the Degree of Progression, 5 J. Pub. ECON. 161, 162 (1976) ("Suppose that two tax schedules give rise to income distributions after tax with nonintersecting Lorenz-curves, then the tax schedule related to the dominated Lorenzcurve can be considered unambiguously more redistributive than the other.").

79 See generally id. at 162 ("If one tax system is everywhere . . more progressive than the other, then it should also be unambiguously more redistributive than the other."); J. Fellman, The Effect of Transformations on Lorenz Curves, 44 Econometrica 823 (1976); N.C. Kakwani, Applications of Lorenz Curves in Economic Analysis, 45 Econometrica 719 (1977).

80 LAMBERT, supra note 67, at 188-90 (summarizing the results of Fellman, supra note 79; Kakwani, supra note 79; Jakobsson, supra note 78). 
poor person increases. Likewise, a rich person's expected income decreases as expected damages increase from $\$ 1,000$ to $\$ 2,000$. Thus, if we measured inequality with these two individuals, the Lorenz curve generated with the legal rule where damages depend on income would strictly Lorenz dominate the curve generated with the legal rule where expected damages do not depend on income. Hence, we can describe the incomedependent-damages rule as redistributive because it reduces inequality.

To conclude this section, redistribution should be understood simply as a reduction in inequality. More specifically and analogously to taxand-transfer redistribution, we can define a legal redistribution as any change in legal rules that reduces inequality. In addition, there is no particularly good reason to limit the idea of redistribution to cash transfers (or their equivalent) from rich to poor. Nor, within this general definition of redistribution, is there a meaningful distinction between something we might call distribution and something else called redistribution. In an economic analysis at least, redistribution is interesting only insofar as it changes the income distribution. It should therefore be construed solely in those terms. ${ }^{81}$

\section{Examples}

Now that we have definitions of efficiency and redistribution we can begin to examine the relationship between them. Before doing this more abstractly, I consider examples from the following three areas: product markets, labor markets, and financial markets. For product markets, I consider the classic case of market power. When firms have market power (ability to influence prices) there is typically both a loss of efficiency and an increase in inequality. Legal rules can improve both efficiency and equity. For labor markets, I consider the conditions under which collective bargaining between unions and firms both reduces inequality and increases efficiency. The analysis of labor markets also analyzes when minimum wage legislation, particularly in conjunction with an optimal tax policy, can both reduce inequality and increase efficiency. Finally, the last example considers financial markets. Information problems in financial markets can lead to both a loss of efficiency and an increase inequality. Legal rules can reverse this situation, reducing inequality while increasing efficiency.

81 As mentioned at the start of this section, supra notes 64-66 and accompanying text, it is not entirely clear how Kaplow and Shavell define redistribution. To the extent that they think about redistribution as functionally equivalent to a tax, however, this is clearly too limited an understanding of redistribution. Legal rules have a far greater range of distributional effects, as the examples in the following section demonstrate. 


\section{Product Markets}

Accompanying the renewed attention in rising inequality is a revived concern in the popular press about the monopolistic practices of firms. ${ }^{82}$ In a meta-analysis of fifty three different studies of horizontal mergers, John E. Kwoka found an average post-merger price increase of 6.04\% "after controlling for all other influences, a result that implies generally adverse competitive effects from these transactions." 83 Among these 53 estimates, 40 , or $75.5 \%$, reported price increases averaging $9.4 \%$. Current merger policy in the U.S. may therefore be anticompetitive. ${ }^{84}$

More generally, when firms have market power, production is inefficient because of restricted output. ${ }^{85}$ Firms with market power have some ability to set prices. Market power can arise when there is only one seller (a monopoly) ${ }^{86}$ or only a few sellers (oligopoly) of some good in a market. ${ }^{87}$ In a competitive market, firms are price takers-any attempt to raise prices will simply send consumers to other producers who are offering the perfectly-competitive market price. ${ }^{88}$ In contrast, firms in lessthan-perfectly-competitive markets have at least some ability to set prices. ${ }^{89}$ In the classic example, a firm with market power can increase its price by reducing output. ${ }^{90}$ By restricting supply, the price will go up. Firms will restrict supply, and raise prices, to maximize their profits.

82 See, e.g., Barry C. Lynn, Cornered: The New Monopoly Capitalism and the Economics of Destruction (2011); David Dayen, Bring Back Antitrust, Ам. Prospect, (Nov. 9, 2015), prospect.org/article/bring-back-antitrust-0.

83 John E. Kwoka, Jr., Does Merger Control Work? A Retrospective on U.S. Enforcement Actions and Merger Outcomes, 78 AnTitrust L.J. 619, 631-32 (2012).

84 Because these studies are not a random sample, the conclusions must be interpreted with some caution, $i d$. at 634 , but the results do lend credence to the more anecdotal concerns of growing market power by firms, supra note 82 .

85 PosNer, supra note 43, at 301 (explaining that "output under monopoly is smaller than under competition").

86 Andreu Mas-Colell et al., Microeconomic Theory 383 (1995) ("The simplest example of market power arises when there is only a single seller, a monopolist, of some good.") (emphasis in original).

87 Id. (defining situations of "oligopoly, in which a number of firms compete in a market") (emphasis in original).

88 Id. ("In the competitive model, all consumers and producers are assumed to act as price takers, in effect behaving as if the demand or supply functions that they face are infinitely elastic at going market prices.”).

89 Id.

90 In fact, it is functionally equivalent to analyze market power either as the firm choosing the price and producing the level of output that consumers demand at that price, or as choosing the quantity to produce and allowing the price to be settled by the level of demand. $I d$. at 384-85 ("The monopolist's decision problem consists of choosing its price $p$ so as to maximize its profits .... An equivalent formulation in terms of quantity choices can be derived by thinking instead of the monopolist as deciding on the level of output that it desires to sell ...."). 
Because output is lower than what would obtain in a perfectly competitive market, the level of output is inefficient. ${ }^{91}$

The existence of market power can increase inequality as well. ${ }^{92}$ This will happen if the owners of the firms with market power are on average richer than consumers who purchase goods or services from them. Consumers are made poorer, because the price of the good is higher, which makes their real incomes lower. When market power increases profits, it increases the incomes of the owners. Of course, if the firms with market power are public companies and their shares distributed equally in society, then the existence of market power would just make everyone poorer, without increasing inequality. But this is almost certainly not the case.$^{93}$ More realistically, the ownership of firms with market power-as is the ownership of all public corporations-is distributed unequally. Market power therefore not only reduces efficiency, but it increases inequality as well. ${ }^{94}$

It follows from this that a legal rule or rules-e.g., antitrust legislation-that limits or reduces monopoly can both increase efficiency and reduce inequality. This is a particularly attractive way to reduce inequality precisely because it involves no net economic cost. The administration of antitrust law is certainly costly, but presumably outweighed by the social benefits of the increase in output. In contrast, taxation, as we have conceptualized it thus far, always involves a positive economic

91 Posner, Economic AnAlysis, supra note 43, at 301 (noting that output is lower "because the monopoly price causes some consumers to substitute other products, products that the higher price makes more attractive. The substitution involves a loss in value. The effect of monopoly is to make some consumers satisfy their demands by switching to goods that cost society more to produce than the monopolized good. The added cost is a waste to society.").

92 Abstractly, whether or not market power increases inequality, it always involves a transfer of wealth. See Posner, Economic AnAlysis, supra note 43, at 302 (describing the increase in price from the competitive to the monopoly level as causing a "transfer of wealth from consumers to producers" in addition to a "deadweight loss," or inefficiency).

93 In 1995, the top $1 \%$ of those in the wealth distribution owned $51 \%$ of the total value of corporate stock (either directly or indirectly through, for example, mutual funds). The top $10 \%$ owned $82 \%$ of the value of these stocks. Edward N. Wolff, Recent Trends in the Size Distribution of Household Wealth, 12 J. Econ. Persp. 131, 139 and tbl. 6 (1998). Given that the distribution of stock ownership is highly unequal, the ownership of monopolistic firms is also highly unequal.

94 Market power can increase other kinds of inequalities as well-e.g., racial inequality. See Ian Ayres, Market Power and Inequality: A Competitive Conduct Standard for Assessing When Disparate Impacts Are Unjustified, 95 CALIF. L. Rev. 669, 669 (2007) (arguing that a company should not be able to raise the business necessity defense in disparate impact litigation if the policy being challenged increases the firm's profits only by exploiting its market power to extract supra-competitive profits). This is yet another case where reductions in inequality can also increase efficiency. Id. at 674 ("[D]isparate impact law can complement antitrust and consumer protection law to make markets more competitive and more equitable. Civil rights law can stimulate market competition by raising the cost of anti-competitive conduct, such as wage-gouging market niches that are disproportionately minority, and thus increase the relative attractiveness of competitive behavior."). 
cost. If the choice was between the antitrust rule and a tax-and-transfer schedule that achieved an identical distributional objective, the wealthmaximizing choice would be the antitrust rule.

\section{Labor Markets}

As the economists Robert Hall and Alan Krueger write, "[L]abor is one of the most heterogeneous products traded in a modern economy. The competitive market for a commodity, where all units are interchangeable and all trade for the same price, could hardly be a worse description of the labor market." 95 In labor markets, departures from the perfectly competitive benchmark abound. There is adverse selection: will the employer be a good or bad one, or will the worker be a good or bad employee? ${ }^{96}$ There is moral hazard: it is difficult to monitor perfectly the efforts of employees. ${ }^{97}$ The employment relationship encompasses enumerable subjects, making contracts necessarily incomplete. ${ }^{98}$ The relationship is more than a spot contract and may last for a substantial amount of time, which opens up the possibility for opportunism on either side. ${ }^{99}$ The process by which workers search for jobs and firms hire workers is beset with all kinds of informational problems, generating "frictional" unemployment. ${ }^{100}$ Search frictions imply the existence of rents, which implies some sort of bargaining or division of these rents, and bargaining power is not likely to be equal between workers and firms or among workers. ${ }^{101}$ Indeed, rent-sharing is pervasive: otherwise identical workers, who should be paid the same in a competitive market, will be paid differently depending on the profitability of the firm they work for. ${ }^{102}$ The existence of rents can lead to wasteful rent-seeking behav-

95 Robert E. Hall \& Alan B. Krueger, Evidence on the Incidence of Wage Posting, Wage Bargaining, and On-the-Job Search, 4 AM. Econ. J.: MAcroecon. 56, 56 (2012).

96 For models of inefficiencies that arise from adverse selection in the labor market, see generally Daron Acemoglu \& Jörn-Steffen Pischke, Why Do Firms Train? Theory and Evidence, 113 Q. J. Econ. 79 (1998); and Bruce C. Greenwald, Adverse Selection in the Labour Market, 53 Rev. Econ. STUd. 325 (1986).

97 Bengt Holmström, Moral Hazard and Observability, 10 Bell J. Econ. 74 (1979); Shapiro \& Stiglitz, supra note 10.

98 For the classic introduction of incomplete contracting into economics, see generally Oliver Williamson, The Economic Institutions of Capitalism (1985). For the application of incomplete contracting to the employment relationship, see generally Paul A. Grout, Investment and Wages in the Absence of Binding Contracts: A Nash Bargaining Approach, 52 ECONOMETRICA 449 (1984).

99 Id.

100 Christopher Pissarides, Equilibrium Unemployment Theory (2d ed., 2000)

$101 \mathrm{Id}$.

102 Several empirical studies find extensive evidence of rent-sharing between firms and workers. See, e.g., David G. Blanchflower et al., Wages, Profits, and Rent-Sharing, 111 Q. J. ECon. 227 (1996); David Card et al., Rent-sharing, Holdup, and Wages: Evidence from Matched Panel Data, 81 Rev. Econ. Stud. 84 (2014). 
ior. ${ }^{103}$ In short, labor markets are likely to be inefficient. As we will shortly see, these inefficiencies can also increase inequality.

\section{a. Collective Bargaining}

Let us consider a particular example, which I will then extend in a few directions. ${ }^{104}$ Consider a labor union bargaining with a single firm. Suppose the firm is contemplating a decision to make an investment in physical capital or in research and development, with the potential to increase productivity and profits. ${ }^{105}$ If the firm does this, the union will have an incentive to bargain for higher wages, in order to capture some of this increase. ${ }^{106}$ This adds an implicit cost to the capital investment, and a firm, anticipating this cost, will either not make the investment or a make a smaller investment than it would in the absence of a union. ${ }^{107}$ This is inefficient: output and productivity are lower than they would be without the union. ${ }^{108}$

Now consider a legal rule that requires unions to bargain with an employer's association, representing an industry or a sector, rather than a single firm. ${ }^{109}$ The union and the employer's association set wages according to the average productivity of the firms in the association, rather than each individual firm. ${ }^{110}$ This changes each firm's investment deci-

103 One area where employee rent-seeking has garnered much attention is in the study of executive compensation. See generally Lucien Bebchuk et al., Managerial Power and Rent Extraction in the Design of Executive Compensation, 69 U. CHI. L. Rev. 751 (2002).

104 The single-firm case follows the analyses in Grout, supra note 98. See also Simon Anderson \& Michael Devereux, Trade Unions and the Choice of Capital Stock, 90 Scandinavian J. Econ. 27 (1988); Matthew Dimick, Productive Unionism, 4 U.C. Irvine L. Rev. 679, 693-97 (2014) (providing an informal discussion of the formal analyses found in the previous two-cited papers).

105 Grout, supra note 98, at 451 (describing a scenario where a firm employs both labor and capital as inputs).

106 Pierre Cahuc \& André Zylberberg, Labor Economics 411 (William McCuaig trans., 2001) ("This characteristic of equipment means that firms have an incentive to invest less if bargaining over wages can be begun at any time, for once the investment has been made, employees are tempted to demand a new round of bargaining in order to benefit from the improved productivity induced by the increase in capital stock.").

107 Id. at $449-50$.

108 Id. at 449 (noting that if the union can renegotiate contracts or contracts are not binding, "inputs [such as physical capital] will not be employed efficiently if the union has any power").

109 In the United States, current labor legislation and regulation, as expressed in the National Labor Relations Act and in the decisions of the National Labor Relations Board (NLRB), directly and indirectly discourage multiemployer, industrial, or sectoral bargaining. This policy is reflected in the blanket prohibition on the NLRB's recognition of multiemployer bargaining units as well as the prohibition of secondary boycott tactics, which discourages coordinated union bargaining. At the same time, there are labor law doctrines that favor the stability of multiemployer bargaining units, after they are voluntarily recognized by both employers and unions.

110 For an analytical comparison of firm-level (decentralized) with industry- or sectorlevel (centralized) collective bargaining, see K.O. Moene et al., Bargaining Structure and Eco- 
sion compared to firm-based bargaining. Since the investment will now increase the wages the firm pays by only a fraction of the amount it would in the previous case, the incentive to invest is much higher in the multi-firm case than in the single firm case. ${ }^{111}$ With larger investments and output, multi-employer bargaining is therefore more efficient than single-employer bargaining. ${ }^{112}$

Multi-employer bargaining also reduces inequality compared to single-employer bargaining. ${ }^{113}$ First, since firms care only about marginal effects when undertaking the investment, aggregate profits can be lower in multi-employer bargaining even though productivity is higher. ${ }^{114} \mathrm{Un}$ ions can increase wages and labor income on average, for example, if unions are able to coordinate their bargaining strategies, as is likely the case under multi-employer bargaining. ${ }^{115}$ This will reduce inequality if

nomic Performance, in Trade Union Behaviour, Pay Bargaining, and Economic PerFORMANCE 63, 109-14 (R.J. Flanagan et al. eds., 1993); Karl Ove Moene \& Michael Wallerstein, Pay Inequality, 15 J. LAB. Econ. 403 (1997).

111 Moene et al., supra note 110, at 109-14.

112 Id.; Moene \& Wallerstein, supra note 110, at 406. Evidence supports the observation that unionization reduces investment when collective bargaining is decentralized (i.e., occurs at the firm level), as in Canada, the United Kingdom, or the United States. See generally Stephen G. Bronars et al., The Effects of Unions on Firm Behavior: An Empirical Analysis Using Firm-Level Data, 33 Indus. Rel. 426 (1994) (finding that unionization is associated with less investment in durable assets, such as research and development, in the United States); Robert A. Connolly et al., Union Rent Seeking, Intangible Capital, and Market Value of the Firm, 68 Rev. Econ. \& Stat. 567 (1986) (finding that unionization is associated with lower investment in research and development in the United States); Kevin Denny \& Stephen J. Nickell, Unions and Investment in British Industry, 102 Econ. J. 874 (1992) (finding that unionization is associated with lower investment rates in the United Kingdom); Barry T. Hirsch, Firm Investment Behavior and Collective Bargaining Strategy, 31 Indus. ReL. 95 (1992) (finding that unionization is associated with lower investment in research and development and physical capital in the United States); Cameron W. Odgers \& Julian R. Betts, Do Unions Reduce Investment? Evidence from Canada, 51 Indus. \& LAB. Rel. Rev. 18 (1997) (finding that unionization is associated with lower net investment rates in Canada). In contrast, unionization does not have such negative effects when collective bargaining is more centralized, as in Europe. See Naercio Menezes-Filho \& John Van Reenen, Unions and Innovation, in International Handbook of Trade Unions 293, 328 (John T. Addison \& Claus Schnabel eds., 2003). A particularly interesting study shows that wage compression associated wit $\mathrm{h}$ centralized wage bargaining in Sweden was consistent with increases in productive efficiency as long as it focused on reducing wage inequalities between firms and did not compress within-firm wage differentials too greatly. Douglas A. Hibbs, Jr. \& Håkan Locking, Wage Dispersion and Productive Efficiency: Evidence for Sweden, 18 J. Lab. Econ. 755, 771 (2000).

113 See generally Moene \& Wallerstein, supra note 110. For evidence that more centralized bargaining structures reduce wage inequality, see generally Michael Wallerstein, WageSetting Institutions and Pay Inequality in Advanced Industrial Societies, 43 Ам. J. Pol. ScI. 649 (1999) (finding that wage-bargaining centralization is the most important factor explaining variation in earnings inequality across developed countries, with other economic and political factors having little or smaller impact).

114 Moene \& Wallerstein, supra note 110, at 406.

115 Matthew Dimick \& Neel Rao, Wage-setting Institutions and Corporate Governance, 44 J. Comp. ECon. (forthcoming 2016). 
those earning capital income are on average richer than those receiving labor earnings. ${ }^{116}$ Second, if firms are heterogeneous with respect to other characteristics that influence productivity, competitive wage-setting or firm-level bargaining will increase inequality among wage earners. ${ }^{117}$ By equalizing wages across firms, multi-employer bargaining then also reduces inequality among those with labor earnings. ${ }^{118}$

This argument can be extended in various ways. Given the list of departures from perfect competition, there may well be inequality and suboptimal investment even without the presence of unions. ${ }^{119}$ Multiemployer bargaining can increase efficiency and reduce inequality even in this case. In addition to physical capital, one could also consider the case of human capital. ${ }^{120}$ Greater centralization in wage bargaining can also have positive effects on job creation, ${ }^{121}$ employment, ${ }^{122}$ or as a kind of insurance against income uncertainty. ${ }^{123}$

\section{b. Minimum Wage Legislation}

A seemingly obvious case where taxes appear to dominate legal rules as a redistributive tool is the one of minimum wage legislation. Several scholars, again both within and without law and economics, have made very strong cases for this conclusion. ${ }^{124}$ The consensus may be mistaken, however, and the minimum wage provides an excellent exam-

116 Id.

117 Moene \& Wallerstein, supra note 110, at 406 ("We characterized the competitive equilibrium in this case and show that it is efficient and unequal in the sense of generating wage differentials that exceed workers' quality differentials.").

118 Id.

119 Pissarides, supra note 100, at 57-58; Pierre CAHUC \& André Zylberberg, Labor ECONOMICs 542-45 (William McCuaig trans., 2001). In these models, bargaining arises from labor market frictions, which generate rents. With contractual incompleteness and bargaining, the "holdup" problem arises.

120 See generally Daron Acemoglu \& Jörn-Steffen Pischke, The Structure of Wages and Investment in General Training, 107 J. PoL. ECON. 539, 564 (1999) (discussing why in the presence of labor market frictions workers will underinvest in general human capital and providing unions as one example of how this inefficiency can be overcome).

121 Steven Davis, The Quality Distribution of Jobs and the Structure of Wages in Search Equilibrium (Nat'1 Bureau of Econ. Research, Working Paper No. 8343, 2001).

122 Lars Calmfors \& John Driffill, Centralization of Wage Bargaining, 3 Econ. PoL'y 13, 24 (1988).

123 See Jonas Agell \& Kjell Erik Lommerud, Union Egalitarianism as Income Insurance, 59 ECONOMicA 295, 303 (1992).

124 For the liberal argument in favor of transfers and against the minimum wage, see Alstott, supra note 3. For the law-and-economics argument, see generally Daniel Shaviro, The Minimum Wage, the Earned Income Tax Credit, and Optimal Subsidy Policy, 64 U. CHI. L. REV. 405, 471 (1997) (arguing that the appropriate tax-and-transfer scheme "could replace such existing social welfare programs . . . and the minimum wage"). 
ple why both taxes and legal rules are necessary to achieve both equity and efficiency. ${ }^{125}$

Let us consider a perfectly competitive labor market. ${ }^{126}$ For the reasons given above, such a market is unlikely to exist. But it will be useful to assume otherwise for the sake of argument-it will demonstrate that minimum wage legislation can be both efficient and redistributive even if labor markets are perfectly competitive.

First suppose such a market without any taxes and transfers. As the familiar supply and demand argument demonstrates, if one imposes a minimum wage higher than the market-clearing wage, it will raise wages, but will reduce the demand for labor. Firms, facing a higher wage, will employ fewer workers. While the market-clearing wage leads to the efficient amount of labor employed, the minimum wage imposes a deadweight loss and is therefore inefficient. Furthermore, by reducing employment for low-wage workers, the classic rebuttal to minimumwage proponents is that it harms the very people it was intended to benefit. ${ }^{127}$

Because of this, several eloquent cases have been made for tax-andtransfer alternatives to the minimum wage. ${ }^{128}$ For example, some argue that the Earned Income Tax Credit (EITC) is superior to the minimum wage. ${ }^{129}$ Under the EITC, the government gives a cash credit, dependent on household income, to those who work. ${ }^{130}$ Because the EITC is a lowwage subsidy, it boosts earnings but also encourages work among those in the lower tail of the income distribution. ${ }^{131}$ But because it does not "tax" low-wage jobs like the minimum wage, 132 it does not have the

125 See David Lee \& Emmanuel Saez, Optimal Minimum Wage Policy in Competitive Labor Markets, 96 J. Pub. Econ. 739 (2012); Jesse Rothstein, Is the EITC as Good as an NIT? Conditional Cash Transfers and Tax Incidence, 2 Aм. Econ. J. Econ. PoL'y 177 (2010).

126 There is a large literature demonstrating that minimum wages can both increase efficiency and reduce inequality in imperfectly competitive labor markets. See, e.g., Daron Acemoglu, Good Jobs Versus Bad Jobs, 19 J. Lab. Econ. 1 (2001); Alan Manning, Monopsony in Motion: Imperfect Competition in Labor Markets (2003); Lee \& Saez, supra note 125 , at 740 .

127 However, this is not necessarily true. Because the minimum wage does increase wages, it can be welfare improving for low-wage workers as long as the wage increase for employed workers offsets the deadweight loss caused by the unemployment effect. See Lee \& Saez, supra note 125 , at 741-42 (demonstrating formally that a minimum wage even without taxes and transfers can increase social welfare). A necessary assumption for this to be true under general conditions is "efficient rationing," i.e., that workers made unemployed by the minimum wage have the lowest ability and/or taste for work. See id. at 741.

128 See generally Alstott, supra note 3; see also Shaviro, supra note 124.

129 See Shaviro, supra note 124, at 474.

130 For programmatic details see Alstott, supra note 3, at 1048 and Shaviro, supra note 124 , at 408 .

131 Shaviro, supra note 124 , at 461-62.

132 See id. at $414-15$. 
purported negative employment effects. ${ }^{133}$ Furthermore, because the EITC is targeted to those with low earnings, it is a more effective tool for redistribution than the minimum wage. ${ }^{134}$ Some workers earning the minimum wage come from households with relatively high income (the "teenager-from-a-rich-household" problem). ${ }^{135}$ Arguably, then, the EITC has all of the benefits-and more-and none of the drawbacks of the minimum wage.

An alternative proposal to the EITC is the Negative Income Tax (NIT). Like the EITC, the NIT transfers rather than taxes income (hence, negative income tax) to those below a certain income threshold. ${ }^{136}$ But unlike the EITC, it does not make work (i.e., any positive labor earnings) a condition of the transfer. ${ }^{137}$ Some argue that the EITC's work requirement reflects an unjustified and paternalistic intrusion into persons' decisions to work or not, and that the NIT is superior on these grounds. ${ }^{138}$ Economically, the criticism of the EITC is that its rate structure is complicated and distortionary. ${ }^{139}$ In this sense, the NIT is arguably less distortionary, and therefore more efficient than the EITC. ${ }^{140}$

As taxes both the EITC and the NIT are distortionary, but some of these inefficiencies increase the scope for minimum wage policies. First,

133 Id. at 408 (explaining that although the minimum wage is a low-wage "subsidy," it "will be affirmatively harmful [to low-wage workers] . . . because it imposes a tax on lowwage employment. . . . Should one favor a low-wage subsidy, the obvious alternative is to finance it out of general revenues" as is done with the EITC).

134 Id. ("The EITC's income-testing and reliance of general revenues make it a far better tool than the minimum wage both for making market work a more viable long-term option and for progressive redistribution.").

135 Id. at $407,418$.

$136 I d$. at $469-70$. My characterization is slightly misleading. According to Shaviro, the main drawback of the EITC is the high effective marginal tax rates it imposes on income earners in the "phase-out" range of the credit. $I d$. at 462 . Shaviro would therefore structure the program so that everyone would receive a lump sum grant (say \$6000) which would eventually be offset by a positive tax rate (say a flat $25 \%$ ). Id at at $469-70$.

137 Alstott, supra note 3, at 977-78 (describing the closely related basic-income and negative-income-tax proposals).

138 See generally id.; see also id. at 990 ("[A moral claim for employment subsidies, like the EITC] discounts the freedom of any low-earner whose vision of the good life does not revolve around market work.") and 991 ("The tension between market work and freedom takes on a special resonance for women, who remain disproportionately responsible for nonmarket work-caring for children, the frail elderly, and so on.").

139 Shaviro, supra note 124, at 466 ("All phaseouts risk creating perverse overall marginal rate structures, especially when, due to the lack of integrated thinking, they are thoughtlessly allowed to compound each other.").

140 Shaviro, supra note 124, at 470-71 (arguing for a NIT over an EITC primarily on the grounds of the EITC's complicated and positive marginal rate structure in the phaseout range of the benefit). On the other hand, if labor supply on the intensive margin (i.e., the decision to work or not) is more important than on the extensive margin (i.e., how hard, or how many hours to work), the EITC can be more optimal than the NIT. See generally Emmanuel Saez, Optimal Income Transfer Programs: Intensive versus Extensive Labor Supply Responses, 117 Q. J. ECON. 1039 (2002). 
because the EITC is a low-wage subsidy, it encourages more work and increases the labor supply among low-wage workers. ${ }^{141}$ But as labor supply increases, employers can offer a lower wage. ${ }^{142}$ Employers then capture a portion of the subsidy intended for low-wage workers. ${ }^{143}$ Thus, the EITC's redistributive effect is muted because of these incidence effects. But it also induces inefficiency, by encouraging more work than is efficient. At the same time, the NIT on balance discourages work, which reduces labor supply and therefore increases wages, in a manner that is similar to the minimum wage (although not dollar for dollar). ${ }^{144}$ The result is perhaps a stronger redistributive effect, but "too little," i.e., inefficient, labor employed. The economist Jesse Rothstein finds that among single-mother working households, $\$ 1$ in EITC spending increases aftertax incomes by $\$ 0.73$, while $\$ 1$ spent on the NIT yields $\$ 1.39 .{ }^{145}$

This is where the minimum wage becomes effective. In the context of the EITC, which drives down wages and increases labor supply away from its efficient level, setting the minimum wage at the market-clearing level can restore efficiency in the labor market. ${ }^{146}$ Furthermore, by establishing a wage floor, low-wage workers now capture all of the EITC subsidy: $\$ 1$ of EITC spending would increase low-wage workers' income by $\$ 1 .{ }^{147}$ Thus, combining the EITC and the minimum wage is both efficient and redistributive.

141 See Rothstein, supra note 125, at 179 ("I find that the EITC produces sizeable reductions in equilibrium wages that offset many of its benefits to low-skill workers."); Lee \& Saez, supra note 125, at 740 ("When the government values redistribution toward low-skilled workers, the optimal tax system over-encourages the supply of low-skilled labor."); see also Shaviro, supra note 124, at 462 ("However, since more than twice as many workers and more than seven times as much earned income are in the positive 19 percent than the negative 37 percent marginal rate bracket, it is plausible that on balance the EITC, by reason of its rapid phaseout, makes the substitution problem [between labor and leisure] worse.”). There is no disagreement among these authors; Shaviro merely more explicitly acknowledges that the increased labor supply induced by the EITC for low-income workers is offset by a labor supply reduction of higher-income workers who are in the "phaseout" range of the EITC.

142 Rothstein, supra note 125, at 179 (noting that the positive effect of EITC is "pushed downward by falling wages."); Lee \& Saez, supra note 125, at 742-44.

143 Rothstein, supra note 125, at 179 ("Employers of low-skill labor capture $\$ 0.36$ via reduced wage bills ....").

$144 I d$. ("The NIT imposes positive tax rates on earnings, leading to net reduction in labor supply among eligible women and thereby to increased wages.").

145 Id. at 177.

146 See Lee \& Saez, supra note 125, at 742-44.

147 Id. at 743 ("With a binding minimum wage . . an EITC expansion would increase after-tax incomes of low-skilled workers dollar for dollar."). 


\section{Financial Markets}

A ubiquitous feature of many modern firms is the "separation of ownership from control" characteristic of the public corporation. ${ }^{148} \mathrm{~A}$ significant source of financing for such corporations is external, either in equity or debt. Financial markets exist to satisfy this demand. Yet external financing creates well-known incentive problems. One of these problems is known as the principal-agent problem. ${ }^{149}$ The "principalagent problem" has been written about extensively and in many ways serves as the organizing principle for much of the corporate law literature in the United States. ${ }^{150}$

The problem is that the owners, the shareholders of the firm, would like the manager to work as hard as possible, but cannot fully monitor or contract on the manager's efforts. ${ }^{151}$ Because the manager receives a salary or only owns a fraction of the firm, she is not the residual claimant on the firm's output and has little reason to supply her best level of effort. ${ }^{152}$ Shareholders must therefore monitor the efforts of the manager, but monitoring uses resources that could otherwise have been more productively

148 The public corporation is characterized by relative distant shareholders who own the corporation, but delegate day-to-day control to professional managers. This type of business organization arose to prominence and the problem of the separation of ownership and control was first posed in the early twentieth century. See Adolf A. Berle \& Gardiner C. Means, The Modern Corporation and Private Property (1932). For a widely-cited economic explanation for this separation, see generally Eugene F. Fama \& Michael C. Jensen, Separation of Ownership and Control, 26 J.L. \& Econ. 301 (1983). For an account that brings out the comparative and political "preconditions" of the separation, see generally Mark J. Roe, Political Preconditions to Separating Ownership from Corporate Control, 53 Stan. L. Rev. 539 (2000).

149 See generally Holmström, supra note 97. After the development of the principal-agent model in economics, it was quickly applied to the study of the corporation and corporate finance. See, e.g., Eugene F. Fama, Agency Problems and the Theory of the Firm, 88 J. PoL. ECon. 288, 291 (1980); Fama \& Jensen, supra note 148, at 306; Michael C. Jensen \& William H. Meckling, Theory of the Firm: Managerial Behavior, Agency Costs and Ownership Structure, 3 J. Fin. Econ. 305, 309 (1976).

150 Margaret M. Blair \& Lynn A. Stout, A Team Production Theory of Corporate Law, 85 VA. L. Rev. 247, 248 (1999) (writing that "[c]ontemporary discussions of corporate governance have come to be dominated by" the principal-agent framework). As they note, it is impossible to reference all of the legal literature, but they cite several applications of the principalagent problem in corporate law scholarship. See id. at 247 n. 1.

151 Jensen \& Meckling, supra note 149, at 308 (explaining that in a principal-agent relationship, "it is generally impossible for the principal or the agent at zero cost to ensure that the agent will make optimal decisions from the principal's viewpoint"). Jensen and Meckling also characterize the shareholder-manager relationship as a special case of the more general agency problem. Id. at 309 ("Since the relationship between the stockholders and manager of a corporation fit the definition of a pure agency relationship it should be no surprise to discover that the issues associated with the 'separation of ownership and control' in the modern diffuse ownership corporation are intimately associated with the general problem of agency.").

152 Samuel Bowles \& Herbert Gintis, Recasting Egalitarianism: New Rules for Communities, States, and Markets 7 (Erik Olin Wright ed.,1998). 
employed. ${ }^{153}$ A contract could be devised which allows the manager to become the residual claimant on the income generated by the corporation, but then "rents" the corporation from the shareholders for a fixed fee. ${ }^{154}$ But while the manager is the residual claimant on the income generated by the firm, she is not a residual claimant on the value of the corporation itself. ${ }^{155}$ The manager may therefore have little incentive to maintain the assets owned by the corporation. ${ }^{156}$ In either case there is a loss of efficiency. Much of the literature on the principal-agent problem is about reducing this inefficiency.

One solution to both problems is to sell the corporation to the manager. ${ }^{157}$ Now the manager is the full residual claimant on the corporation and has all of the incentives to maximize the value of the firm. ${ }^{158}$ If the manager is poorer than the owners, then this move also reduces inequality by transferring the capital income once received by relatively richer shareholders to the relatively poorer manager. ${ }^{159}$

As a class, shareholders may be richer than the manager. Indeed, this is why external finance exists, because the entrepreneur-manager does not have the capital herself to run or expand the corporation. ${ }^{160} \mathrm{But}$ of course, managers, and CEOs in particular, may be quite wealthy individuals, and rising executive compensation is surely an important source of income concentration at the top of the distribution. ${ }^{161}$ Furthermore, responding to the principal-agent problem by making managers part-

153 Jensen \& Meckling, supra note 149, at 308 (defining the sum total of agency costswhich constitute efficiency losses - to include the monitoring expenditures of the principal, as well as any bonding expenditures of the agent and the residual loss in productive output).

154 Bowles \& GinTis, supra note 152, at 7.

155 Id.

156 Id.

157 Bowles \& Gintis, supra note 152, at 7-8 ("The result of these incentive problems is that a highly concentrated distribution of capital is often inefficient: there may exist a more egalitarian distribution, in which the worker becomes the owner of the firm's capital goods which, by more effectively addressing the inventive, monitoring, and maintenance problems involved, allows general improvements in well-being . . ..").

158 Id.

159 Id.

160 Another standard-and powerful-justification for the separation of ownership and control in firms is the greater risk-bearing capacity of the (wealthy) owners. This larger capacity to absorb risk is due largely in part to the greater wealth of the owners, who are sufficiently wealthy to diversify their risk. See Fama \& Jensen, supra note 148, at 333 (mentioning the benefits of specialization by separating risk-bearing and management functions).

161 Jon Bakija, Adam Cole, \& Bradley T. Heim, Jobs and Income Growth of Top Earners and the Causes of Changing Income Inequality: Evidence from U.S. Tax Return Data (Working Paper, 20122010), https://web.williams.edu/Economics/wp/BakijaColeHeimJobsIncome GrowthTopEarners.pdf (analyzing data to "demonstrate that executives, managers, supervisors, and financial professionals account for about 60 percent of the top 0.1 percent of income earners in recent years, and can account for 70 percent of the increase in the share of national income going to the top 0.1 percent of the income distribution between 1979 and 2005"). 


\section{owners was an intellectually important source for the rise of "pay-for- performance" among firm managers. ${ }^{162}$}

But the example merely serves to illustrate a much wider phenomenon. Indeed, the argument can be extended to make all of the corporation's employees-rank-and-file workers as well as managers-owners of the corporation. ${ }^{163}$ In this case, the redistributive effects of transferring ownership are far more obvious and stronger. ${ }^{164}$ Furthermore, this economics-of-information argument is also applicable to many kinds of financial market transactions where there is inequality and imperfect information. ${ }^{165}$ The more general point is that in capital markets with less

162 For the intellectual lodestone, see Michael C. Jensen \& Kevin J. Murphy, Performance Pay and Top-Management Incentives, 98 J. Pol. Econ. 225, 243 (1990). Jensen and Murphy found a weak relationship between shareholder wealth and executive compensation. They interpreted these findings to indicate that corporate executives were paid too little, not that performance pay was a weak tool to motivate managers. Id. at 226-27 ("Public disapproval of high rewards seems to have truncated the upper tail of the earnings distribution of corporate executives. Equilibrium in the managerial labor market then prohibits large penalties for poor performance, and as a result the dependence of pay on performance is decreased."). However, they explicitly acknowledged that this is one interpretation of their evidence. Id. at 227 ("Our results are consistent with several alternative hypotheses . . .."). And recent research has not been kind to their hypothesis that larger executive compensation would improve either efficiency or shareholder wealth. See generally Bebchuk et al., supra note 103 (finding little evidence that executive compensation packages can be explained in terms of inducing better performance from managers); see also Marianne Bertrand \& Sendhil Mullainathan, Are CEOs Rewarded for Luck? The Ones Without Principals Are, 116 Q. J. Econ. 901, 902-03 (2001) (finding that executive compensation is responsive to "luck" factors-changes in firm performance outside of the manager's control—but also that executive pay is less responsive to luck in firms with better corporate governance); Thomas Piketty et al., Optimal Taxation of Top Labor Incomes: A Tale of Three Elasticities, 6 Am. Econ. J.: ECon. Pol'y 230, 262 (2014) (finding that top tax rate cuts are associated with top one percent pretax income shares but not higher economic growth, that United States CEOs "pay for luck" is quantitatively more prevalent when top tax rates are low, and that international CEO pay levels are negatively correlated with top tax rates, even controlling for firms' characteristics and performance, which indicates a substantial "rent-seeking" component of CEO income).

163 This is in fact the main argument of Bowles \& Gintis, supra note 152.

164 Note that the case for worker ownership is more open to debate than the preceding examples, partly because there is less empirical support for the efficiency of worker-owned firms. Further, if worker-owned firms were more efficient than the prevailing public corporation, one would prima facie expect worker-owned firms to dominate public corporations, via a kind of "natural selection" argument. As noted previously, supra note 160, a large advantage of the separation of ownership and control is the specialization of risk-bearing and management functions. Asking workers to own the firms they work for requires them to bear more risk, which given their lower wealth and the lack of diversification, they are less inclined to do. This could explain the relative paucity of worker-owned firms in the economy. Bowles and Gintis's response is that large enough asset redistributions will make workers more willing to bear risk, and that policies like insurance for market risks or credit extended to worker-owned firms on favorable terms can also increase workers' appetite for risk. See supra note 152, at 379-83. While I may not be fully convinced by Bowles and Gintis's argument, the main purpose of the example is to demonstrate the broader point that there is nothing in economic theory that dictates that there will always be a tradeoff between efficiency and equity.

165 See, e.g., Bernanke \& Gertler, supra note 10, at 90. 
than perfect information, inequality is also inefficient. ${ }^{166}$ Thus, legal rules and policies that encourage greater "asset redistribution" can both increase efficiency and reduce inequality.

\section{Efficient Legal Redistribution}

The foregoing examples contradict the double-distortion argument that legal redistributions will be inefficient. If legal redistribution is not inefficient, and perhaps even efficient, then it is not true that "the legal system is less efficient than the tax system in redistributing income." In these cases, the law is more efficient than the tax system in redistributing income.

How far does this result generalize beyond the specific examples just discussed? This section will explore that question. The simple answer is that there is no necessary relationship between redistribution and efficiency. A policy change could reduce inequality but also make everyone worse off. Such a policy change would be both redistributive and Pareto inferior relative to the status quo policy. But there is no a priori reason why a policy change could not reduce inequality and make everyone better off. Such a policy change would be both redistributive and Pareto efficient. More likely scenarios are cases of redistribution where some are made better off and others worse off. Yet even here the implications for efficiency are neither obvious nor straightforward. If the winners could compensate the losers, the redistribution will be Kaldor-Hicks efficient; if not, redistribution is inefficient under either criterion.

These possibilities are illustrated by Figure 4. This figure is similar to Figure 1, but we now add the role of legal rules. Let $x$ denote the legal regime. (For instance, $x$ could be a set of legal rules $x=\left(x_{1}, x_{2}, \ldots, x_{n}\right)$ that comprises the legal system.) A different legal regime will produce income, denoted $y$, for each person 1 and 2: $y_{1}$ and $y_{2}$. Persons 1 and 2 then get a certain level of utility from their income, which, again, is a function of the legal regime. That is, $U_{l}=U\left(y_{l}(x)\right)$.

Figure 4 essentially assumes that legal rules can produce allocations of income anywhere within and including the Pareto frontier. In other words, legal rules can achieve any allocation of income that is technologically feasible. There are two main justifications for this. The first is the

166 See, e.g., Hoff, supra note 10, at 412 (making a general argument and summarizing the economics-of-information argument about efficiency, inequality, and capital and credit markets). Consider the case of a poor consumer and rich lender. Tax-and-transfer redistribution may be the most effective policy prescription in this case, which increases the wealth of the poor and makes her more credit worthy. Yet this would not be tax-and-transfer in the way that Kaplow and Shavell think about it, since it would be accompanied by a market-corrective and efficiency-enhancing function. For this reason, it would be more appropriate to think about this prescription as a legal rule (to correct behavior) than as a pure tax and transfer. I pursue this discussion further infra Part III.C. 
conclusion we have just drawn from the previous examples. Those examples demonstrated that changes in legal rules can increase both efficiency but also reduce income equality. ${ }^{167}$ Alternatively, as the double-distortion argument shows, sometimes legal rules can reduce both inequality and efficiency. ${ }^{168}$ Thus, in Figure 4, changes in legal rules that move the allocation of income in a northeast or southwest direction primarily affect the efficiency of the allocation. In contrast, changes in legal rules that move the allocation in a northwest or southeast direction primarily affect the level of income equality.

For another justification, we can invoke the Coase theorem. ${ }^{169}$ The Coase theorem is well known for saying that achieving the efficient allocation of resources does not depend on the distribution of legal entitlements. ${ }^{170}$ As long as bargaining between agents is possible and transaction costs are sufficiently low, agents will have an interest in engaging in and paying for the most efficient activities. Less well appreciated is the fact that the Coase theorem says that legal entitlements will also always affect the distribution of economic rewards without influencing the allocation of resources. ${ }^{171}$ Since property rights are divisible in highly minute ways, ${ }^{172}$ it is a reasonable approximation to say that property rights could be adjusted to achieve a large range of allocations within and on the Pareto frontier. ${ }^{173}$ Part IV.B below explores further the implications of the Coase theorem, including the role of transaction costs.

167 See supra Part II.C.

168 See supra Part I.

169 The first expression of the "Coase theorem" is found in R.H. Coase, The Problem of Social Cost, 3 J.L. Econ. 1 (1960), although George Stigler first coined the phrase. See G. Stigler, The Theory of Price 113 (3d ed. 1966) (stating the "Coase theorem" as predicting that "under perfect competition private and social costs will be equal").

170 Stewart Schwab, Coase Defends Coase: Why Lawyers Listen and Economists Do Not, 87 Мich. L. Rev. 1171, 1174 (1989) (stating the "weak version" of the Coase theorem as the proposition that the allocation of resources will be independent of the distribution of legal entitlements and a "strong version" that bargains are efficient regardless of the initial legal entitlements).

171 Schwab calls this the "Distributive Corollary of the Coase Theorem," which he defines, "With zero transaction costs, initial entitlements cannot be justified on efficiency grounds, and so should be awarded on the basis of need or desert." See id. at 1195; see also Guido Calabresi, The Pointlessness of Pareto: Carrying Coase Further, 100 Yale L.J. 1211, 1212 (1991) (arguing that "any given society is always or will immediately arrive at a Pareto optimal point given transaction costs").

172 On the ability to parcel out property rights, as in a "bundle of sticks," see Thomas C. Grey, The Disintegration of Property, in XXII Nomos, Property 69 (J. Roland Pennock \& John W. Chapman eds., 1980).

173 It is surprising that the Distributive Corollary of the Coase Theorem and the choice of law versus taxes in redistributing income are not discussed together more. I discuss this further, infra Part IV.B and accompanying text. 
As an implication of these assumptions, note that the possible allocations of income induced by the legal system are: (1) "continuous"there are no gaps, or holes, in the possible income distributions-(2) "symmetric" - the possible income allocations are distributed similarly on either side of the line of equality, meaning that there is no reason why efficiency would require some systematic inequality between persons 1 and 2-and (3) "convex"-meaning that one can draw a line between any two points on the utility possibility frontier and say within the feasible set of allocations. Both of these assumptions are strong, but strong and similar assumptions are not unusual within economic analysis. These three assumptions mainly exist to help simplify the inquiry. Below, in Part IV.C, I will relax both of these assumptions and explore the implications for doing so. Nothing much of substance changes.

We can now investigate Figure 4 in more detail. Figure 4 represents four different lines. The utility possibility (Pareto) frontier defines the set of all feasible economic allocations. This captures the Pareto set. All movements toward the frontier are Pareto improving, points along the line are Pareto efficient, while moves beyond the frontier are not feasible. The social indifference curve describes changes in the distribution of wealth between individuals 1 and 2 that leave total wealth unchanged. Along this line, reducing inequality is purely a tradeoff between individuals 1 and 2. Despite that, there are legal changes that produce allocations that both reduce income inequality and increase economic output. To see this, begin with the status quo allocation, represented by point $A$. There are two fine-grained dashed lines that cross through this point. Everywhere above (below) the horizontal dashed line increases (decreases) person 2's utility, while everywhere to the left (right) of the vertical line decreases (increases) person 1's utility. In addition, two coarser-grained dashed rays emanate from the origin, with the lower line passing through point $A$. Every point within these two lines reduces income inequality.

These four lines define the universe of possibilities between inequality and redistribution. First, every point below the solid, social-indifference curve and within the two dashed rays is both redistributive and inefficient. These areas are labeled $I R$ for inefficient redistribution. Within this region, points to the left of the vertical dotted line and below the horizontal dotted line make both individuals worse off. These are redistributions for which no one would advocate. However, points with the $I R$ region that are above the horizontal dotted line and to the left of the horizontal dotted line are allocations that improve the welfare of person 2. Kaplow and Shavell's income-dependent damage rule is an example of this kind of legal redistribution. 
In contrast, every point above the solid, social-indifference curve and between the two dashed rays is both redistributive and efficient. There are both Kaldor-Hicks and Pareto-efficient legal redistributions. Points that are above the social-indifference curve, but to the left of the horizontal dotted line are efficient and improve the welfare of person 2, but leave person 1 worse off. Since person 1 could hypothetically compensate person 2, these allocations are Kaldor-Hicks efficient. However, allocations within the two dashed rays, above the horizontal dotted line, and to the right of the vertical dotted line are both redistributive and Pareto efficient. Points in this area not only reduce inequality, but also leave both persons better off.

Thus, one cannot say that a redistributive legal rule is distortionary as a general matter. To answer this question, one must first identify the effect of the particular legal rule in question. In this sense, redistribution effectuated through the tax system is a special kind of legal change, one that, moreover, is always accompanied by distortions in economic behavior. ${ }^{174}$ This is because of the particular nature of the legal rule being enacted and enforced. For example, income earners pay a certain percentage of their income in cash, which is collected by the government, and then the cash is transferred to other individuals. A government schedule that assigned distinct commodity bundles to individuals based on their observable output poses a very different set of legal rules for achieving a desired distribution of economic rewards. Yet it would also certainly have similar distortionary impacts if it had redistributive objectives (in addition to being much harder to implement). Conversely, as the examples in this Part have demonstrated, other kinds of legal rule changes may both increase efficiency as well as reduce inequality.

\section{Optimal Legal Redistribution}

As we have just seen, some legal rules can be redistributive in a strong sense, yet also be output enhancing. This is the strongest case against Kaplow and Shavell's argument that the tax system should be exclusive mechanisms for redistributing income. In this section, I look more closely at cases where legal changes are redistributive but also inefficient. It might seem that in this situation we are firmly back in doubledistortion territory and that one should reject legal rules that have such consequences. However, I argue that even when legal rules are inefficient, the double-distortion argument is still not always convincing because even if taxation is distortionary, we still need to compare the legal

174 Kaplow and Shavell, supra note 1, at 667 (claiming generally that "income taxes and transfer payments distort incentives to work, limiting the degree to which it is socially desirable to employ the income tax system to redistribute income"). The assumption that the taxand-transfer system is always distortionary is relaxed in Part IV.D. 
distribution to the optimal tax policy. ${ }^{175}$ If the legal redistribution is less inefficient than this policy, social welfare will be higher with the legal redistribution than under the optimal tax policy.

While this much has been acknowledged, we can also go further. ${ }^{176}$ In this Part, I will also argue that legal rules are more likely to be more efficient than taxation precisely in those cases where inequality is of greater concern. In particular, more inequality justifies larger tax distortions under the optimal tax policy. Likewise, if the public or policymakers find inequality to be of graver concern (either because attitudes about inequality change or because the externalities of income inequality have increased), the optimal tax policy will also justify larger tax distortions. Yet because of these greater distortions, it is more likely that a more redistributive legal rule that produces a given amount of inefficiency will be more efficient than the optimal tax policy.

The introduction of "optimal" and "welfare" requires introducing another criterion of normative economic analysis. ${ }^{177}$ I therefore first discuss the concept of social welfare and its maximization. Following this, I show that some inefficient legal redistributions can dominate, in welfare terms, the optimal tax policy. This is more likely the case when we judge the social welfare cost of inequality to be higher or when inequality itself is higher.

\section{A. Social Welfare}

Thus far, efficiency has been used in this article to be understood as wealth maximization. But a society might want to instead maximize wel-

175 See, e.g., Blumkin \& Margalioth, supra note 1, at 13 (arguing that comparison of costs of both tax and legal systems need to be made to judge which is superior); see also infra note 176.

176 This is, in fact, the crux of many of the critiques of the double-distortion argument. See, e.g., Sanchirico, supra note 5, at 1027-31 (arguing that the optimal (i.e., welfare-maximizing) policy may award higher damages to poorer plaintiffs when the legal rule differentially affects the rich and poor, which implies, relative to Kaplow and Shavell's argument, an inefficient allocation of resources); Blumkin \& Margalioth, supra note 1, at 3, 11-14 (arguing, for example, that once the administrative and compliance costs of tax administration are included, redistributive legal rules, which may not incur similar costs, can be less inefficient-or more efficient - than the tax system); Liscow, supra note 1, at 2482-83 (observing that "redistribution through legal rules may be inefficient and costly, but so is redistribution through taxation" and that, accordingly, some redistributive legal rules, although not Pareto superior, can be "more efficient than raising taxes").

177 As already indicated in the Introduction, I reserve the term "efficient" to refer to changes in social wealth and use "optimal" to describe changes in welfare. See supra note 42 and accompanying text. 
fare or utility. ${ }^{178}$ Welfare and wealth are not the same thing ${ }^{179}$ and, indeed, depending on which objective we prefer, the policy recommendation may well be different. ${ }^{180}$ This will be particularly the case when evaluating policies with different distributional consequences. ${ }^{181} \mathrm{I}$ will illustrate these differences and contrasts in this section.

Maximizing social welfare, that is, making social welfare as large as possible, requires thinking about a social welfare function. ${ }^{182}$ If we simply add up everyone's utility, the allocation we should choose is the one that makes total utility as large as possible. ${ }^{183}$ An individual's utility function itself needs defining. The assumption, well-supported by evidence, is that people experience diminishing marginal utility of money. ${ }^{184}$ Simply put, if I have only ten dollars to my name, those ten dollars will be much more valuable to me than ten dollars I have in addition to another ten thousand dollars. ${ }^{185}$ This idea is critical for understanding the difference between wealth and welfare maximization. It means that transferring money from the rich to the poor can increase social welfare, even at the cost of wealth, because the poor value additional income more than the rich. ${ }^{186}$

We can again illustrate these ideas with Figure 2. In addition to the Pareto, utility possibility (Pareto) frontier, within which represents all of the feasible allocations, social welfare introduces the social indifference curve. A social indifference curve represents all of the allocations that

178 Drawing from philosophers of utilitarianism, utility can be roughly understood as happiness. See, e.g., Posner, Economic ANAlysis, supra note 43, at 13 (distinguishing between "expected utility," from the economics of risk and uncertainty, and "utility in the sense used by philosophers of utilitarianism, meaning (roughly) happiness"). Sufficient for our purposes will be a definition of utility used by economists, which is the value or "usefulness" an individual derives from some good.

179 Wealth would measure the market value of goods, while utility would measure individuals' valuation of money or those goods. See supra note 178.

180 Much of the literature critiquing the double-distortion argument acknowledges that welfare maximization should be the objective, especially when discussions of inequality are concerned. See, e.g., Fennell \& McAdams, supra note 1, at 1-2 (noting that tax and legal policy should be welfare maximizing); Liscow, supra note 1, at 2481 (stating that, in contrast to wealth maximization, "traditionally, economists have sought policies that maximize not wealth but rather 'social welfare,' the sum of individuals' utility . . ..”).

$181 \mathrm{Id}$.

182 MAS-Colell et al., supra note 86, at 825 (“[A] social welfare function . . . aggregates individuals' utilities into social utilities."); HINDRIKs \& MYLES, supra note 50, at 425 (noting that one measures "the welfare of society by aggregating the individual consumers' welfare levels").

183 HindRIKs \& Myles, supra note 50, at 425-26 (describing the process by which a hypothetical social planner maximizes social welfare).

184 For one study, among countless others, see Layard et al., The Marginal Utility of Money, 92 J. Pub. Econ. 1846 (2008).

185 See Stiglitz, supra note 96, at 94-97 (discussing the principle of diminishing marginal utility).

186 See infra notes $187-91$ and accompanying text. 
give the same level of social welfare-in this case, the same total utility between persons 1 and 2. In Figure 2, there are two social indifference curves, with the curve that is northeast of the other curve representing a higher level of social welfare. Intuitively, as curves move outward from the origin, they give greater utility to both individuals. Notice that while points $A$ and $B$ are equally Pareto efficient, social welfare would easily prefer point $B$ to point $A$ or $C$, since it moves society to a higher indifference curve and unambiguously increases social welfare. Notice also that point $B$ would clearly be preferred to point $C$, and that $B$ is Kaldor-Hicks efficient relative to $C$. However, also observe that the move from $C$ to $A$ would also be Kaldor-Hicks efficient. But in this case, the gain in wealth would not justify the increase in inequality, and social welfare would prefer $C$ to $A$. Thus, social welfare and Kaldor-Hicks efficiency agree on the move from $C$ to $B$, but disagree on the move from $C$ to $A$.

\section{B. Optimal Tax Policy}

The concept of social welfare and its maximization are critical in what is called the "optimal tax" literature. ${ }^{187}$ The optimal tax literature takes as given the problem that taxation will distort behavior and create disincentives which lower economic output. ${ }^{188}$ On the one hand, taxation can increase social welfare by redistributing income and reducing inequality, according to the principle of diminishing marginal utility of money. ${ }^{189}$ On the other hand, taxation can reduce social welfare by distorting economic incentives and lowering economic output. ${ }^{190}$ The objec-

187 The optimal tax literature is enormous, but one can trace its origins to a very influential paper by James Mirrlees. J.A. Mirrlees, An Exploration in the Theory of Optimum Income Taxation, 38 REv. ECON. STUd. 175 (1971). For an informal introduction to the literature, see generally N. Gregory Mankiw et al., Optimal Taxation in Theory and Practice, 23 J. Econ. Persp. 147 (2009). For a formal introduction, see Bernard Salanié, The Economics of TAXATION 83-122 (2d ed. 2011).

188 Mirrlees, supra note 187, at 175 (“As a result of using men's economic performance as evidence of their economic potentialities, complete equality of social marginal utilities of income cease to be desirable, for the tax system that would bring about that result would completely discourage unpleasant work."). Classical economists, such as Edgeworth, endorsed "complete equality of fortunes" based on the principal of declining marginal utility of income. See Salanié, supra note 187, at 85. But they did not know how to model "the trade-off between efficiency and equity" and how "confiscatory taxation . . . reduces production and thus the size of the social cake," although they were aware of that risk. Id. at 87.

189 See supra note 186 and accompanying text.

190 These efficiency losses may arise from a variety of sources, including the administrative and compliance costs of tax collection. See, e.g., Blumkin \& Margalioth, supra note 1, at 11-14. In the optimal tax literature, as well as in Kaplow \& Shavell's double-distortion argument, the sole cost of taxation typically derives from the disincentive to work. See, e.g., Mirrlees, supra note 187, at 175-76 (assuming the incentive to work depends on taxes, but that the "costs of administering the optimum tax schedule are assumed to be negligible"); Kaplow \& Shavell, supra note 1, at 667-68 (modeling their hypothetical case where taxation distorts labor incentives, but a redistributive legal rule distorts both labor and care-taking incentives). 
tive is to then find that tax function that optimally balances this trade-off between equity and efficiency-to achieve the highest social welfare consistent with the smallest efficiency cost. ${ }^{191}$

One can draw two conclusions from the optimal tax literature that will be useful for the following discussion. ${ }^{192}$ The first is that higher inequality can justify greater taxation-and hence a larger economic distortion. ${ }^{193}$ When inequality is high, redistribution is particularly desirable. More redistribution requires more taxes, and hence a larger distortion, but this is justified by the greater welfare benefit of redistribution in the context of high inequality. Conversely, if incomes were perfectly equal, there will be no welfare benefit to redistribution and only an economic cost. In this case, no taxation is justified. The second conclusion is that the optimal tax depends not just on the level of inequality, but also on how much we (or the policy maker) care about any particular level of inequality. ${ }^{194}$ For example, a utilitarian cares only about aggregate wealth and effectively puts zero weight on the level of inequality. 195 Since taxation can only reduce wealth, no taxation is justified under the utilitarian's preferences. ${ }^{196}$ On the other hand, a Rawlsian cares only about the welfare of the least well off. ${ }^{197}$ This objective places a great

191 See Mirrlees, supra note 187, at 207 (referencing the trade-off between "labour-discouraging effects" of taxation and the "redistributive benefits"); see also SALANIÉ, supra note 187, at 83 ("The study of optimal direct taxation must take into account disincentive effects on labor supply. ... [O]nly since Mirrlees ... do we have a model that allows us to discuss the trade-off between equity (the search for a redistribution that implements social views) and efficiency (minimizing distortions induced by the tax system).").

192 Much of the optimal tax literature tries to determine the optimal "shape" of the tax schedule, meaning how progressive the schedule should be. See Peter Diamond \& Emmanuel Saez, The Case for a Progressive Tax: From Basic Research to Policy Recommendations, 25 J. ECON. PersP. 165 (2011) ("A large academic literature has developed models of optimal tax theory to cast light on the problem of optimal tax progressivity.").

193 This is in fact one of Mirrlees's initial suggestions. See Mankiw et al., supra note 187, at 160 (Mirrlees "suggested that tax rates would generally be higher in less equal societies.").

194 For a discussion of the redistributive implications of different social welfare functions, which can be interpreted to reflect different policy objectives, see MAs-Colell, supra note 86, at $825-29$.

195 HindRIKs \& MYLES, supra note 50, at 425-26 (describing a utilitarian social welfare function as one where the "utility of one consumer can be substituted perfectly for that of another with the utilitarian social welfare function ...."). Because of perfect substitution of utility between individuals, a transfer from rich to poor will not increase social welfare. This implies that taxation has no benefits and only costs, and thus authorities should not undertake it.

196 Id.

197 HindRIKs \& MYLES, supra note 50, at 425-26 (describing a Rawlsian social welfare function as one that maximizes the welfare of the least well-off person and where "no substitution is possible ...."). It is well known that Rawls's Difference Principle is nonwelfarist. The Difference Principle states that society should maximize the amount of primary goods-not the level of utility-going to its poorest members. John E. Roemer, Equality of Resources Implies Equality of Welfare, 101 Q.J. Econ. 751, 753 (1986) ("[Rawls] wishes to maximize the bundle of primary goods going to the least well off, not to maximize the utility of that 
deal of weight on inequality and chooses the tax level that maximizes the welfare of the poorest citizen, giving no weight to the welfare of any richer member of society. ${ }^{198}$ Any other level of consideration we give to equity lies between these two extremes. ${ }^{199}$

\section{Distributional Judgments}

As just demonstrated, the optimal tax literature seeks to identify the ideal tax function that balances the economic cost against the reduction in inequality in order to maximize social welfare. This optimal tax, which identifies the amount of economic loss, depends on how much inequality a policy maker is willing to condemn. As also just demonstrated, in a utilitarian's calculus, any level of inequality is acceptable, while those committed to a Rawlsian objective are prepared to tolerate quite a lot of economic loss in order to reduce inequality.

Thus, how much distortion maximizes social welfare depends on how much we are willing to condemn inequality. This also strongly affects whether the legal system or the tax system should be used to redistribute income. Depending on how much society or a policy-maker is willing to reduce inequality, an inefficient legal redistribution may or may not be a preferable alternative. For example, if the tolerance for inequality is relatively high, social welfare may be highest under the optimal tax policy, which redistributes little at relatively low economic cost. An inefficient legal redistribution may reduce inequality more, but may deliver lower social welfare because of greater economic distortions. In contrast, this same legal redistribution may well be superior to the optimal tax policy under a Rawlsian social welfare function, which creates larger economic distortions. Thus, whether legal rules are more efficient than taxes in redistributing income depends on the social welfare objective that society or policy makers choose.

This idea can also be illustrated with the aid of Figure 5. Figure 5 depicts three different social indifference curves derived from different social welfare functions, a utilitarian, a Rawlsian, and an intermediate one. The status quo point is point $A$. The dashed line represents the resource constraint caused by increasing the level of taxation required to implement a desired distribution of resources. As we move toward the line of equality, the economic cost of doing so increases. Perfect equality

group.”). Economists nevertheless call a social-welfare function that maximizes the welfare of the poorest Rawlsian because of the obvious similarity.

198 MAS-Colell, supra note 86, at 828 (noting that a Rawlsian social welfare function "will have strong egalitarian implications. In fact, the preference for equality is quite extreme" and while the costs of taxation may prevent complete equality in this case, "the purely utilitarian social optimum is significantly more unequal than the [Rawlsian] optimum").

199 As in HindriKs \& MYLEs, supra note 86, at 425-26, an observer could call these intermediate social welfare functions. 
can be achieved if there is a complete confiscation of income and wealth, which is then equally distributed. However, there is no economic incentive to work in such a society, so there is no income to redistribute. As each indifference curve shows, the amount of redistribution we should tolerate depends on our normative judgment. The utilitarian cannot justify any change from the status quo point $A$. The Rawlsian wants to maximize the utility of the least well off person, person 2, and so chooses the highest vertical position on the tax loss curve, represented by point $C$. Intuitively, the intermediate judgment chooses a point between these two on the tax cost curve, point $B$, which reduces inequality more than in $A$, but less than in $C$.

The critical insight comes by examining regions $X$ and $Y$. Region $Y$ is the area created by the "lens" of the two intersections of the utilitarian and intermediate indifference curves. All allocations within this region give higher social welfare than at point $B$, but at less economic cost. Hence, if one were a utilitarian, no point within region $Y$ would be justified, but if one were willing to condemn inequality at least as much as the intermediate judgment, any legal redistribution within region $Y$ would be preferred to point $B$. Similarly, the same thing can be illustrated by region $X$, which is the area under the intermediate indifference curve, but above the Rawlsian indifference curve. An intermediate judgment would not endorse any allocation within region $X$, but a Rawlsian would prefer any point within region $X$ to point $C$, the Rawlsian's most preferred taxand-transfer allocation.

Thus, the choice of whether to use the legal system or the tax system depends on how much inequality society is willing to tolerate. ${ }^{200}$ Generally, legal alternatives become more attractive when society's "taste" for equality increases. Put another way, the possibility of finding a less inefficient legal redistribution increases as we become less tolerant of inequality.

\section{Level of Inequality}

For very closely related reasons, the choice between law or tax as redistributive tools also depends on the level of inequality itself. Keeping fixed our judgment about the distribution of income, the social-welfare maximizing level of taxes will be higher when inequality is higher. ${ }^{201}$ If there is no inequality, for example, there is no social welfare gain from

200 An observer could ask which social welfare function should be endorsed. Economists have refrained from answering this question, considering it a value judgment that economic social science cannot answer. This difficulty stems from the problem of interpersonal comparisons of utility, which will be discussed infra notes 224-31 and accompanying text.

201 Because there is greater scope for increasing social welfare when inequality is higher for reasons of diminishing marginal utility of money. See supra notes 184-86 and accompanying text. 
reducing inequality. Likewise, when there is only a modest level of inequality, there is only a modest gain from reducing it and hence only a small loss in economic output is justified. In contrast, when inequality is high, the social welfare gain from reducing inequality is also high. This larger social gain justifies a larger economic cost. As a result, the economic distortion caused by taxation will also be higher. It follows from this that which redistributive tool we use depends on the level of inequality.

The reasoning is similar to the example given in the previous subsection. If inequality is low, the optimal tax policy will have relatively low tax rates and little economic distortion. If a legal redistribution lowers inequality further, but is associated with larger economic costs, the tax policy may be the social-welfare maximizing policy. However, if inequality is high, the optimal tax policy will entail a greater economic distortion. In this case, the legal redistribution may instead be the socialwelfare maximizing policy.

In addition, Figure 6 depicts this argument graphically. Figure 6 represents two status quo allocations, given by points $A$ and $C$. The straight line running through points $A$ and $C$ indicates that society enjoys the same wealth at each allocation, but that $A$ is more unequal than $C$. Holding our judgment of inequality fixed at an intermediate level, the optimal tax policy would be to choose point $B$ in case $A$, and point $D$ in case $C$. However, notice that although social welfare is higher at point $B$ than at point $A$, point $D$ is higher than both. Since the status quo point $C$ has lower inequality than $A$, one does not need to move very far to point $D$, and incurs lower economic cost to do so. Hence, social welfare is higher at $D$ than at $A, B$, or $C$.

This graphical analysis also implies that if there are legal allocations between the two social indifference curves when beginning at $A$, they would be preferred to the optimal tax solution, under which society only gets to $B$. On the other hand, if we begin at a lower level of inequality, status quo point $C$, then none of the legal redistributions between the two social indifference curves would be preferable to the optimal tax solution at point $D$. Once again, the conclusion is that whether an inefficient legal redistribution is desirable or not depends on the level of inequality. In this case the conclusion has an appealing generality: if the level of inequality is higher, the set of legal redistributions that yield higher social welfare becomes larger.

\section{Counterarguments}

This Part considers potential objections to my argument. I first address the claim that even if legal rules might be more efficient than taxation in redistributing income, this does not defeat Kaplow and Shavell's 
broader argument that efficiency should be the sole criterion for evaluating legal rules. Next, I consider more directly the implications for transaction costs in my argument. This leads to a further discussion that examines more critically the assumptions of "continuity" and "symmetry" I made in the main analysis. Finally, I consider the implications for my argument of, first, the possibility of efficient tax-and-transfer policies and, second, what is called "corrective" taxation, as distinct from income taxation.

\section{A. On the Exclusivity of Efficiency}

One potential objection to my argument is that a legal redistribution that also increases social wealth-that is, is efficient-is not inconsistent with Kaplow and Shavell's argument. One reading of their argument is that efficiency should be the sole criteria for evaluating legal rules. Indeed, their conclusion states that their "argument . . . suggests that it is appropriate for economic analysis of legal rules to focus on efficiency and to ignore the distribution of income in offering normative judgments." 202 For instance, return to the monopoly example. In that case, the argument might be that we should endorse the antitrust rule for its effects on efficiency, regardless of its distributional consequences. Considering the antitrust rule's consequence on inequality is therefore not necessary. Although they do not say this, perhaps Kaplow and Shavell assume only inefficient legal redistributions because efficient legal redistributions do not challenge this conclusion.

This response is not convincing, for several reasons. First, the argument that efficiency should be the sole criterion for normative analysis is not the argument they make, and is at best only an implication of it. Their main claim is that the tax system is "more efficient" than the legal system in redistributing income. Yet, as the argument above has demonstrated, this claim is false: not only may legal redistributions be more efficient than the tax system, but they may also increase efficiency. Therefore, the legal system should be used to redistribute income, and can even be superior to the tax system. This debate does not question the role and importance of efficiency. Within this law-and-economics discussion, everyone agrees that efficiency is important. The only question is whether legal rules or the tax system is the most efficient-least costly-means of redistribution.

Still, there may be something to this objection. Favoring the legal system over the tax system for distributional objectives in these cases still depends on these legal redistributions being efficient. If everyone agrees that efficiency is important, does not efficiency therefore still 
"trump" equity in the economic analysis of law? In response, the most that one can say about efficient legal redistributions is that they are both efficient and redistributive. Why should the efficiency effect take priority over the distributive effect? In fact, I will argue that the distributional effect deserves at least equal normative priority with efficiency.

Distribution deserves normative priority over efficiency because social welfare maximization dominates wealth maximization as criteria of economic and legal analysis. Several shortcomings of Pareto efficiency that were only alluded to previously make this point clear. One crucial fact about Pareto efficiency is that it cannot make any judgment about the distribution of the allocation. ${ }^{203}$ It is possible that an allocation that makes everyone equally well off could be Pareto efficient. Likewise, an extremely unequal allocation could also be Pareto efficient. ${ }^{204}$ Related to this shortcoming is the problem that Pareto efficiency does not possess any criteria for choosing among the set of Pareto optimal allocations. As long as there is no "waste," Pareto efficiency is indifferent between any possible number of economic allocations. ${ }^{205}$ A third drawback of the Pareto criterion is that it is unable to rank certain allocations. ${ }^{206}$ If a different allocation made one person much better off and a second person only slightly worse off, we might be willing to accept such a change, particularly if the "winner" in this change was willing and able to compensate the "loser." But in fact, Pareto efficiency can say nothing about this change, because someone is made worse off. ${ }^{207}$ For this reason, some allocations are incomparable under Pareto efficiency. ${ }^{208}$

203 An example of this is given in Figure 1. In that figure, points $A$ and $B$ are both Pareto efficient, both the $B$ allocation is more equal than the $A$ distribution. Despite the difference in equity, Pareto inefficiency is indifferent between the two. Hindriks \& MYLES, supra note 50, at 438 ("[E]ven though an allocation is Pareto efficient, there is no implication that it need be good in terms of equity.").

204 Id.

205 I read this shortcoming as slightly different than the first. The first shortcoming is that Pareto efficiency cannot make any distributional judgments. The second shortcoming is more general and says that Pareto efficiency is indifferent about allocations that are Pareto efficient. HINDRIKS \& MYLES, supra note 50, at 439 ("Pareto-efficiency does not embody any concept of justice, and highly inequitable allocations can be efficient under the criterion. [Second,] [i]n, in many situations there are very many Pareto-efficient allocations, in which case the criterion provides little guidance for policy choice.").

$206 I d$. ("Another failing of the Pareto preference ordering is that it is not always able to compare alternative states. In formal terms, it does not provide a complete ordering of states.") (emphasis in original).

207 An example of this is illustrated in Figure 1. In that figure, Pareto efficiency cannot rank points $B$ and $C$. Facing a choice between these two, Pareto efficiency cannot tell us whether one is preferred to the other. For instance, a change in allocation from $C$ to $B$ would make person 1 worse off, even though person 2 could compensate person 1 .

208 Note that indifference is not the same thing as incomparability. See HINDRIKS \& Myles, supra note 50, at 439 ("If the preference order were indifferent between two states, then they are judged as equally good. Incomparability means the pair of states simply cannot be ranked."). 
It is in these cases of incomparability that the concept of KaldorHicks efficiency comes in handy. As previously defined, an allocation is said to be Kaldor-Hicks's efficient relative to another if the "winners" can compensate the "losers." 209 Note that this compensation is typically thought of as merely hypothetical. ${ }^{210}$ If compensation did actually occur, the change in allocation would be Pareto efficient as well. ${ }^{211}$ Nevertheless, Kaldor-Hicks efficiency is useful precisely in those situations where allocations are incomparable under the more austere Pareto criterion. If it is at least feasible for winners to compensate the losers, then it must be true that total wealth in society has increased. ${ }^{212} \mathrm{We}$ can then say that the new allocation is more efficient than the old. Kaldor-Hicks efficiency is also said to be more useful than Pareto efficiency since most changes in economic allocations involve both winners and losers. ${ }^{213}$

Although the idea of Kaldor-Hicks efficiency can solve the comparability problem, it cannot address the indifference or distributional problems. Like Pareto efficiency, Kaldor-Hicks efficiency is indifferent to a change in the allocation of resources, so long as the winners can compensate the losers. ${ }^{214}$ Whether the change also involves an increase or decrease in income inequality is irrelevant to Kaldor-Hicks efficiency. ${ }^{215}$

Social welfare analysis avoids these problems of the efficiency criterion. In fact, choosing among income distributions the one that maximizes to social utility - the social welfare function-solves all of the shortcomings of the efficiency concepts listed previously. ${ }^{216}$ Although there may be more than one allocation that achieves the same, and the highest, level of social welfare, under certain assumptions the social welfare criterion does not face the problem of an infinite indifference be-

209 See Coleman, supra note 42, and accompanying text.

210 See Posner, Economic Analysis, supra note 43, at 14.

211 Coleman, supra note 42, at 98 ("Were the payment transaction costless and full compensation given to the losers, Kaldor-Hicks distributions would be transformed into Paretosuperior ones."). For this reason, Kaldor-Hicks efficiency is sometimes called potential Pareto efficiency. See Posner, Economic Analysis, supra note 43, at 14.

212 Returning to Figure 1, we can now judge allocation $B$ more efficient than allocation $C$, since in a move from $C$ to $B$, person 2 could compensate person 1 .

213 Posner, Economic Analysis, supra note 43, at 14.

214 See id. at 14 (discussing the concept of Kaldor-Hicks efficiency and the requirement that winners be able to compensate losers, regardless of the distributive consequences).

$215 \mathrm{Id}$. at 15 (explaining that efficiency, including the Kadlor-Hicks criterion, "does not answer the question whether the existing distribution of income and wealth is good or bad, just or unjust").

216 For a general discussion of welfare maximization and its advantages vis-à-vis efficiency, see HindRIKs \& Myles, supra note 50, at 424-27, 436-41. 
tween allocations. ${ }^{217}$ It also solves the problems of distribution. ${ }^{218}$ For example, if we take a dollar away from a wealthy person and give it to a poor person, we will increase social welfare. ${ }^{219}$ This follows naturally from the principle of diminishing marginal utility of money. ${ }^{220}$ Social welfare increases since the poor person values that dollar more than the wealthy person. Hence, unlike Pareto or Kaldor-Hicks efficiency, socialwelfare maximization is not indifferent to the level of economic inequality. Finally, social welfare maximization can also address the incomparability problem. ${ }^{221}$ Suppose the difference between two different allocations is that the welfare of the poor is much higher in the first than in the second, while the welfare of the rich is only slightly lower in the second than in the first. As we previously saw, Pareto efficiency cannot compare these two allocations. ${ }^{222}$ Kaldor-Hicks would endorse the first as long as the poor could compensate the rich. In addition, the socialwelfare criterion would also endorse the first as long as total social welfare is higher in the first than in the second-which is the conclusion given diminishing marginal utility of money.

Although both social welfare maximization and Kaldor-Hicks efficiency can address the Pareto problem of comparability, they may well disagree about which allocation is more desirable. For example, KaldorHicks efficiency clearly endorses an allocation change that increases inequality, but in which the rich can compensate the poor. Yet the new allocation may or may not be social welfare maximizing. Suppose, for example, that a large wealth gain of the rich is only slightly larger the wealth loss to the poor. Although the change is Kaldor-Hicks efficientthe rich could compensate the poor, and still be better off - the allocation may reduce social welfare because, by the principle of the diminishing marginal utility of money, the uncompensated welfare loss of the poor

217 Referring again to Figure 1, note that any point along the utility possibility, or Pareto, frontier is Pareto efficient. Since the curve is continuous, the number of Pareto efficient allocations is infinite. However, when the social indifference curve is introduced, there is a unique allocation that maximizes social welfare. Nevertheless, since the utility possibility frontier may be nonconvex (e.g., "wavy" rather than curved), the welfare-maximizing allocation may also not be unique. Notwithstanding this concession, welfare maximization reduces the number of "desirable" allocations in this way.

218 HindriKs \& MYles, supra note 50, at 425 (explaining that the "equity considerations" of society, or the social planner, are "[e]mbodied" within a social welfare function).

219 See STIGLITZ, supra note 46, at 108 ("[I]f the extra utility that a poor person gets from an extra dollar of income (his marginal utility) exceeds the loss in utility to the rich person of losing a dollar (his marginal utility), then total social welfare (the sum of the utilities) will increase by transferring the dollar.").

220 See supra note 184 and accompanying text.

221 See STIGLITZ, supra note 43, at 104 ("The social welfare function provides a basis for ranking any allocation of resources, unlike the Pareto principle, in which we can only say that one situation is better than another if everyone is at least as well off, and someone is better off.").

222 Supra notes 206-08 and accompanying text. 
may exceed the welfare gain of the rich. For the same reason, for an increase in inequality to increase social welfare, the gain of the rich must be substantially larger than the loss to the poor. Consider the limiting case for a useful example. An allocation change that increases the wealth of the rich, but leaves that of the poor unaltered, would unambiguously increase total social welfare. In general then, the social welfare criterion and Kaldor-Hicks efficiency will give different answers about whether an economic allocation should or should not be endorsed relative to another. Yet that they might agree also indicates that social welfare incorporates both equity and efficiency into its evaluation of an economic allocation. ${ }^{223}$

Despite these advantages, there are some well-known critiques of social welfare. The best-known critique challenges the assumption that one can make interpersonal comparisons of wellbeing. ${ }^{224}$ While we can accept that individually I would feel different about ten dollars depending on whether I was rich or poor, we cannot be so certain about the change in total utility when changing the incomes between individuals. ${ }^{225}$ This is simply because utilities are not directly observable. ${ }^{226} \mathrm{In}$ addition, perhaps a rich person values ten more dollars even more than a poor person, even if both have diminishing marginal utility of money. ${ }^{227}$ Perhaps this is why the rich are rich and the poor are poor!228

223 STIGLiTZ, supra note 46, at 104-06 (explaining how a social welfare function allows one to balance the trade-offs between efficiency and equity). As Stiglitz notes, efficiency is just as much a part of welfare maximization as is equity: "Obviously, society is better off [in welfare terms] if everyone is better off-this corresponds to the Pareto principle." Id. at 103.

224 See generally Lionel Robbins, Interpersonal Comparisons of Utility: A Comment, 48 ECon. J. 635 (1938); see also Hindriks \& Myles, supra note 50, at 443-46.

225 Yew-Kwang Ng, A Case for Happiness, Cardinalism, and Interpersonal Comparability, 107 ECON. J. 1848, 1848 (1997) ("After the indifference-curve or ordinalism revolution in the 1930's, modern economists are very adverse to the more subjective concepts and very hostile to cardinal utility and interpersonal comparisons of utility."). The basic economic theory of consumption requires only that individuals be able to rank their preferences for bundles of commodities (ordinal), not that they be able to quantify the utility they get from each commodity bundle (cardinal).

226 Robbins, supra note 224, at 637 (writing that other economic theories "were assumptions which had been verified by observation or introspection, or, at least, were capable of such verification. The assumptions involving interpersonal comparison were certainly not of this order. . . . Jevons had said, 'Every mind is inscrutable to every other mind and no common denominator of feeling is possible." ").

227 Posner, Economic AnAlysis, supra note 43, at 502 ("Since the shape and height of people's marginal utility curves are unknown, and probably unknowable, the possibility that wealthier people's marginal utility curves are higher on average than poorer people's cannot be dismissed, at least when wealth differences are not extreme.").

228 Since utilities are not directly observable, one might argue that the assumption of identical utility curves is as good as the assumption of different utility curves. In answer to this, see PosNER, supra note 43, at 502 ("Yet mightn't income and the marginal utility thereof be, within limits anyway, positively correlated-on the theory that the people who work hard to make money and succeed in making it are, on average, those who value money the most, having given up other things such as leisure to get it?") (emphasis in original). 
There are several possible responses to the criticism of interpersonal utility comparisons. One is that if it is possible to determine a cardinal and bounded index of preferences for individuals, then interpersonal comparisons of utility are indeed possible. ${ }^{229}$ In addition, there is some empirical justification for the belief that individuals indeed have roughly similar utility functions. ${ }^{230}$ Another answer to the interpersonal comparability objection is that a social welfare function captures less a verifiable claim about interpersonal comparisons-especially those claims about the relative positions of winners and losers (e.g., the poor and the rich, respectively, in cases of redistribution) — and more an inescapable value judgment made by citizens or a policy maker. ${ }^{231}$

Whatever one thinks about the criticisms of social welfare and their responses, it need not detain us in the debate about whether taxes or legal rules should be used to reduce economic inequality. The reason is that both arguments require making interpersonal comparisons. ${ }^{232}$ Social welfare maximization is as critical for the case of redistributive taxation as it

229 Daniel M. Hausman, The Impossibility of Interpersonal Utility Comparisons, 104 Mind 473, 480 (1995) ("If it is possible to determine a 'correct' cardinal and bounded index of preferences for individuals that is unique up to a positive linear transformation, then . . . there is, I contend, one right way to make interpersonal utility comparisons."). This simply means that interpersonal comparisons are possible in principle. It does not dispose of the challenge of measuring utilities or preferences, or other objections to utilitarianism as a desirable normative principle, such as that its implications are unfair in certain situations. Id. at 483-85 (summarizing different criticisms of a solution to the incomparability problem on the grounds that it is unfair).

230 All consumers have very similar underlying preference orderings. All consumers prefer more income to less, and households with similar incomes make very similar divisions of expenditures between alternative groups of commodity bundles. For instance, the amount of income spent on food is quite similar, even though the types of foods purchased differs between households. As Hindriks and Myles write, "In modeling such consumers, it is possible to assert that they all have the same utility function guiding their choices. This makes their utilities directly comparable." Hindriks \& MYLEs, supra note 50, at 444.

231 As Kaplow and Shavell themselves point out in separate work, many cite the economist Lionel Robbins for the claim that interpersonal comparisons of utility are impossible. KAPLOW \& SHAvell, supra note 1, at 27 n. 20. Yet Robbins himself viewed this attribution as incorrect, and explained that "the common stipulation that different individuals have equal capacities for satisfaction involves a value judgment rather than a scientifically verifiable hypothesis, and that the need for making value judgments when formulating policy recommendations should be understood not as a deficiency but rather as an inevitability." Id. They also cite the economist Ian Little, who argued that statements about the relative welfare of individuals could be more or less scientific, but drew a clear line between those statements and the inherently normative character of policy recommendations derived from them. In sum, even if different individuals' utility functions were comparable, we would still be making a value judgment about the desirability of redistribution. Id. And if a value judgment is inescapable, we can interpret a social welfare function as reflecting a normative claim about inequality. As we have seen, a variety of normative judgments are possible, ranging from the utilitarian case (wealth maximization) to the Rawlsian case (maximize the utility of the poorest person or household). See supra notes 42, 50 and accompanying text.

232 See the discussion of optimal tax policy supra Part III.B. 
is for reducing inequality through legal rules.. ${ }^{233}$ Indeed, this is no less true for Kaplow and Shavell as for other economists and law-and-economics scholars. In their book, Fairness versus Welfare, Kaplow and Shavell fully commit themselves to a social welfare position, arguing that "social decisions should be based exclusively on their effects on the welfare of individuals . . ." 234 Thus, as long as one takes a welfarist position to the question of distributive justice, the interpersonal comparability problem is inescapable. Consequently, it has little bearing on the specific debate this Article addresses.

The conclusion is that welfare maximization takes priority over wealth maximization. Accordingly, social policy should balance both efficiency and equity - efficiency should not be the exclusive criterion for evaluating legal rules. In the case of antitrust regulation, there is no reason to give priority to its positive efficiency effects. Antitrust regulation should be endorsed because it increases social welfare, both by increasing efficiency and reducing inequality. Note that in the antitrust scenario we fortunately do not face a tradeoff between efficiency and equity. In other cases, such a tradeoff will be inescapable. Nevertheless, in these situations, welfare maximization requires that we give weight to both efficiency and equity. Thus, efficiency is not the only criterion by which legal rules (or other social policies) should be evaluated.

\section{B. On the Pareto Frontier: Transaction Costs and the Coase Theorem}

Another interpretation of Kaplow and Shavell's argument is that when legal rules should be chosen exclusively because they are efficient, they mean Pareto efficient rules. If policymakers adopt Pareto efficient legal rules, the implication is that any other rule would be inefficient. This logic would then rule out cases of efficient legal redistribution. Arguably, the rule that Kaplow and Shavell choose in their example is just such a Pareto efficient legal rule: strict liability. Strict liability perfectly leads actors to internalize their externalities, equating both private and social marginal benefits and costs. As the argument might go, because strict liability is Pareto efficient, any other legal rule would be inefficient.

233 Id.

234 Kaplow \& SHavell, supra note 15, at xvii. Note that this statement is a significant departure from their statement in their double-distortion argument, which emphasizes efficiency rather than welfare: "[Our argument] suggests that it is appropriate for economic analysis of legal rules to focus on efficiency and to ignore the distribution of income in offering normative judgments." Kaplow \& Shavell, supra note 1, at 677. Despite that change, it is clear they remain committed to their double-distortion argument. See generally KAPLOW \& SHAVELL, supra note 1. 
This section demonstrates that this conclusion does not follow from the identification of a Pareto efficient legal rule. This discussion will also provide an occasion to bring into the analysis the role of transaction costs and the Coase theorem.

The rebuttal to this counterargument is that nothing about the concept of Pareto efficiency implies that a Pareto efficient point will be unique. ${ }^{235}$ There can be many, and possibility infinite Pareto efficient allocations. The same goes for legal rules as well. Thus, there can be two or more legal rules that are both Pareto efficient-or at least yield the same level of efficiency. At the same time, their distributional consequences will typically be quite different. Thus, while an alternative legal rule may not improve efficiency, it may still reduce inequality without any loss in efficiency. This outcome would still be superior to redistribution through taxation.

We can use Kaplow and Shavell's own example of tort law to demonstrate this. ${ }^{236}$ Consider first a negligence rule. It is well known that the negligence rule leads individuals to adopt the efficient level of care. ${ }^{237}$ Under this rule, a person must only pay for harm to others if the level of precaution taken by that person is unreasonably low. Facing such a rule, this person will choose the reasonable level of care. As in Learned Hand's famous formula, the reasonable level of precaution is precisely the one that equalizes marginal benefits and costs. ${ }^{238}$ Hence a person will choose the efficient level of care. However, because this level of care is reasonable, she will also not be liable for harm caused to another. These individuals will therefore receive no "transfers" from the harm causer.

In contrast with the negligence rule, suppose that a court adopts a strict liability rule in cases of products liability. Now the harm-causertypically the company that produced the defective product—must pay for all harm caused. This rule still leads to the efficient level of care, since it forces the producer to fully internalize all of its costs, including the harm caused to others by its defective products. With respect to efficiency,

235 This should be obvious from standard economic presentations of the idea of Pareto efficiency. See, e.g., Stiglitz, supra note 46.

236 This example will compare the negligence rule in general tort law and the strict liability rule in products liability. Liscow, supra note 1 , at $2486-88$, also compares both rules in a nuisance/pollution example. But the products liability case seems even more apt than the pollution case considered by Liscow.

237 See, e.g., Marcel Kahan, Causation and Incentives to Take Care under the Negligence Rule, 18 J.L. STUD. 427, 429 (1989) ("Under perfect conditions, a negligence rule will provide incentives for injurers to take the optimal level of care.").

238 One can casually identify the Learned Hand Test with the negligence rule and interpret both as leading to efficient behavior. See, e.g., Liscow, supra note 1, at 2486-87, 2486 n. 18. However, it is also possible to perceive some ambiguity in the Learned Hand Test, some interpretations of which would lead to inefficient behavior. See John Prather Brown, Toward an Economic Theory of Liability, 2 J.L. STUD. 323, 331-35 (1973). 
therefore, the outcomes are identical under either the negligence or strictliability rules. ${ }^{239}$ However, the distributional effects are quite different. ${ }^{240}$ Under the negligence rule, the plaintiffs receive no compensation from the harm causer. In the abstract tort setting, plaintiffs are unlikely to be any more or less wealthy than defendants. Therefore, the lack of transfers is of little concern, because the redistributive impact would be small. Plaintiffs, however, do receive some compensation under the strict liability rule. Moreover, producers will be, on average, wealthier than consumers. In this case, the redistributive rationale makes sense, and strict liability can foster a reduction in inequality without a loss of efficiency.

The first implication for this example is to underscore the point that the existence of a Pareto efficient legal rule does not imply that any alternative legal rule will be inefficient. Pareto efficiency is not unique, and therefore there may be more than one legal rule that is Pareto efficient. The second implication is stronger. If the choice of legal rules we face is between rules that are all Pareto efficient, on what grounds are we to evaluate them? Efficiency is not a helpful criterion, because they all satisfy that condition. Within a legal-economic analysis, the only basis on which to choose among this set of rules is distributive. Thus, to put this another way, if legal rules put society on the Pareto frontier, the only criterion available for evaluating legal rules is equity.

Of course, society is unlikely to be on the Pareto frontier, and if we were there, we wouldn't need to worry about tax distortions. Furthermore, this means there is scope for legal rules to increase efficiency. But this does not cut in Kaplow and Shavell's favor, because if there is scope for increasing efficiency there are likely legal rule changes that simultaneously reduce inequality as well.

It is worth dwelling on this argument for a little longer. Guido Calabresi has made the interesting contention that society is in fact always on the Pareto frontier. ${ }^{241}$ If the Pareto principle were a unanimity requirement, "why wouldn't any change that belonged in the [Pareto] set have already been made? Since, by definition, no one would in any way be hurt by the change, why would anyone object?"242 Thus, "what is efficient ...." 243 The obvious answer to this claim is transaction costs: are there not allocation changes that would make everyone better off, but which cannot be made unanimously because transaction costs preclude

239 Liscow, supra note 1, at 2486-87 (observing that both negligence and strict liability rules lead to the same level of care).

240 Id. at 2487 ("Although there is no difference in the behavior of the [harm causer], there is a difference in the distribution of money.").

241 Guido Calabresi, The Pointlessness of Pareto: Carrying Coase Further, 100 YALE L.J.

1211, 1212 (1991).

242 Id. at 1216.

243 Id. 
us from doing so? Calabresi has "no doubt that failures of knowledge, organization, and compensation often keep us from what, if it could be done, would make us all better off." 244 But his response is that "transaction costs are no different from any other costs," and thus transaction costs "help define the Pareto possibility frontier." 245 Accordingly, "a move to the frontier and a shift of the frontier are, plain and simply, the same thing." 246

The implication of this reasoning is that distributive concerns are inescapable in legal analysis and evaluation. Because society is always on the Pareto frontier, any change in allocation will involve winners and losers. These are distributional changes that make welfare comparisons essential. We can carry this further. Since we are on the Pareto frontier, from an efficiency point of view, any point on that frontier is equally desirable. Pareto efficiency gives us no basis for choosing among the Pareto set. If this is the case, equity is the only basis on which we can evaluate the choice of allocations. As we will see in the next section, welfare maximization can provide a justification for reintroducing efficiency into the analysis, but of course equity must be considered as well.

\section{Non-Convexities}

Earlier, I justified my argument for efficient and optimal legal redistributions by using figures that assumed continuous, symmetric, and convex utility possibilities curves. This assumes that there is some set of legal rules that can achieve any allocation within the set created by that curve, as in Figure 4. For example, in response to the continuity assumption, one could argue that there are significant "gaps" within these figures, and that not every allocation is feasible, including some of those within the region of efficient legal redistributions.

In response to this objection, the continuity assumption is really just a simplification. It is almost certainly true that not every allocation within the set created by the utility possibility frontier is feasible. Yet all of our examples so far have given us reasons to believe that there are many, and perhaps many more, allocations that are feasible. Furthermore, supporters of the double-distortion argument would no doubt believe that there are legal rules than can be Pareto-improving, as well as inefficient legal rules that can lower income inequality. If this were so, it would be strange if there were not legal rules that were not only efficient, but also redistributive. To assume otherwise would be to assume that any gaps coincide precisely in the area of efficient or optimal legal redistributions.

244 Id. at 1218.

245 Id.

246 Id. at 1219. 
The objections to the assumptions of symmetry and convexity are somewhat more serious, but still do not pose any real obstacle to the argument. For example, one could read Figure 2 as assuming that the optimal social welfare corresponds to a set of legal rules that gives both individuals exactly equal income. But quite apart from the distortionary effects of legal rules or taxes, this point may be an impossibility simply because, technologically, an economy may require different tasks of varying complexities that demand that certain workers be paid more or less than others. Thus, rather than a convex curve, the utility possibilities frontier may bow inwards exactly in the region of perfect equality. In addition, different individuals may simply have different abilities, which would again mean that optimal point may entail some inequality and, especially, that the utility possibilities curve may be asymmetric.

Nevertheless, it should be apparent that none of these assumptions remove the more fundamental possibility that there can exist some legal rules that both reduce inequality and increase efficiency. Lack of continuity implies that the set of legal rules is not infinite. But this set may still be quite large. Either lack of convexity or symmetry may mean that perfect equality is impossible with welfare maximization. But they do not rule out the possibility that reductions, even significant ones, are possible.

\section{Efficient Tax-and-Transfer Policies}

So far this Article has assumed, along with Kaplow and Shavell, that the tax system is distortionary. In fact this may not exclusively be the case. That is, tax-and-transfer policies can also have positive efficiency consequences. Although Kaplow and Shavell do not make this argument, it is a potential objection to the claim that legal redistributions can be efficient. The counterargument to this Article's claim is that redistribution through taxation can be efficient as well. The possibility of efficient, redistributive taxation requires us to reevaluate the choice of law versus tax in making distributive economic policy. Yet, as this subsection argues, even where the tax-and-transfer system may produce efficiencies, we cannot also rule out the use of law. Once again, the best distributive economic policy will most likely be a mix of legal rules and taxation.

To see how taxation can increase total wealth, consider the following example. ${ }^{247}$ While individuals' incomes depend on the amount of labor they supply, they also depend on how much they invest in their education. ${ }^{248}$ For moderate or low-income individuals, however, access

247 The following example is from Karla Hoff \& Andrew B. Lyon, Non-Leaky Buckets: Optimal Redistributive Taxation and Agency Costs, 58 J. Puв. Econ. 365 (1995).

$248 I d$. at 367 (building a model in which individuals not only choose their labor supply, but also how much education to obtain). 
to education in turn depends on access to credit, for example, student loans. ${ }^{249}$ And credit markets will be inefficient when information about individuals' abilities is private. ${ }^{250}$ Because lenders cannot perfectly observe the abilities of borrowers or their future earning potential, the costs of lending, reflected in higher interest rates, increase. ${ }^{251}$ High interest rates put education out of reach of low-wealth individuals. ${ }^{252}$ Redistribution, by increasing individuals' collateralizable wealth, can lower interest rates and increase investment in education. ${ }^{253}$ Depending on circumstances, the increase in education can offset the distortions to labor supply caused by taxes, leading to Pareto improvements in the economy. ${ }^{254}$

The implication is that, just as with efficient legal redistributions, there can be efficient tax-and-transfer policies. When tax redistribution reduces wealth, the choice is easy. Because the efficient legal redistribution increases wealth, it unambiguously dominates redistribution through taxation. But when redistribution through both legal rules and taxation is efficient, why choose legal rules over the income tax system in these cases?

Even if tax redistribution can be efficient, this is no argument for choosing taxes at the exclusion of legal rules. If the choice is between efficient tax redistribution and efficient legal redistribution, then there is no choice: both can be implemented. If redistribution through taxation is efficient but the legal redistribution inefficient, then a comparative analysis of the social welfare consequences of each policy option must be undertaken. And so forth. In short, the choice between taxes or legal rules depends on the specifics in each case. There is still no general rule that instructs us that legal rules should never be used to redistribute income. Thus, the existence of efficient tax-and-transfer policies does not rule out the use of legal rules to also redistribute income.

$249 I d$. at $367-68$.

250 Id. at 366 ("When there is private information in an economy, some transactions that would be mutually beneficial if all agents had the same information are not compatible with the incentives of the transactors ....").

251 Id. at 367 ("Some of those who borrow will rationally undertake investments in higher education with negative expected present value because part of the cost of failure is shifted, through default, to others. . . . In general equilibrium, it raises the costs of borrowing.").

252 Id. at 367-68 ("[Borrowing costs], reflected in high interest rates, may be so high that no one in that wealth class has an incentive to borrow, and so zero investment in human capital occurs.").

253 Id. at 367 ("We show that a grant that increases individuals' collateralizable wealth and that is paid out of labor taxes can yield Pareto improvements.").

254 Id. at 368 ("We do not eliminate the adverse impact of taxation on compensated labor supply, but we show that the beneficial net impact on investment in human capital may be more important than the impact on labor hours."). 


\section{E. Legal Rules and Corrective Taxation}

As the efficient tax-and-transfer example demonstrates, taxation in general need not be distortionary. But it is nevertheless still a tax. And as the economics of information literature has shown, taxes and subsidies can frequently play a role in correcting for various kinds of market failures. ${ }^{255}$ Indeed, as is well known, any type of legal rule or regulation can be instantiated as a tax or subsidy. ${ }^{256}$ To reproduce a strict liability legal rule, for example, the government could levy a tax on all harm caused by an individual or legal entity. The implication of this is that taxation could be used to achieve all of the efficiency and distributive objectives that we could have in mind for the use of legal rules. Taxation would be superior to legal rules in redistributing income.

This argument against legal rules fails because it does not consider the very important differences between corrective taxation and income taxation. The difference between corrective taxes and legal rules and regulations is merely formal. Both corrective taxes and legal rules explicitly and intentionally seek to change behavior-for any possible purpose, to correct for market failures, increase efficiency, reduce inequality, or whatever. There is, however, an important difference between, on the one hand, legal rules and corrective taxation and, on the other, income taxation, especially as understood by Kaplow and Shavell. The objective of income taxation is not to change behavior, but to raise revenue-either to produce public goods or redistribute income. ${ }^{257}$

Indeed, the reason that Kaplow and Shavell and the optimal tax theorists believe income taxes are the best instruments for redistribution is that they track the very thing that is redistributed: income. The best income tax would be the one that has the least effect on behavior. Even better than an income tax would an endowment tax - a kind of lump-sum tax assessed on individuals' income-earning potential, which would have no effect on behavior, and therefore no efficiency loss. ${ }^{258}$ But in the ab-

255 A well-known paper in economics establishes that the competitive equilibrium of an economy with incomplete markets and imperfect information is generically not even constrained Pareto efficient. See generally Bruce Greenwald \& Joseph Stiglitz, Externalities in Economies with Imperfect Information and Incomplete Markets, 101 Q.J. EcoN. 229 (1986). For this reason, there is nearly always a role for government to improve economic efficiency through corrective taxation.

256 Shaviro, supra note 124, at 411-14 (discussing the "interchangeability" of taxes, government spending, and regulation).

257 One could also say more directly that the purpose of an income tax is to redistribute income. See Liam Murphy \& Thomas Nagel, The Myth of Ownership: Taxes and JusTICE 76 (2002) (discussing the purpose of income taxation, which is to raise revenue either for redistribution, spending on public goods, or both).

258 "In order for a tax to be lump sum, the consumer on whom the tax is levied must not be able to affect the size of the tax by changing their behavior." HindRIKS \& MYlEs, supra note 50, at 428. The idea of lump-sum taxation is further discussed, infra notes 266-72 and 
sence of information on individuals' abilities, income is the closest proxy. 259

The institutional choice under debate then is not the choice between legal rules and taxes in general, but between behavior-altering legal rules and corrective taxation, on the one hand, and distortion-minimizing income taxation on the other. To extend their argument, Kaplow and Shavell would contend that both corrective taxation and legal rules should be chosen solely based on their efficiency effects. Neither should have distributive concerns, while the income tax should be the sole instrument for redistributing income. To extend my argument, there is no reason why corrective taxes could not simultaneously increase efficiency and reduce inequality. ${ }^{260}$ Provided that that is the case, both corrective taxes and income taxes should be used to redistribute income.

One could have a debate between the choice of legal rules and corrective taxation. ${ }^{261}$ But, at least in the context of this Article's debate, it would not be a very productive one. Because they have the same objectives, the choice between law and corrective taxation would be made based on issues of administrative efficiency and agency expertise and competency. Is the levying of taxes on inefficient behavior less costly than judicial oversight? Do the taxing authorities have the professional competence and expertise necessary, not just to raise taxes, but to regulate the conduct in question? Addressing these issues is beyond the scope of this Article. Moreover, it seems doubtful that a general rule, rather than case-by-case consideration, would be the answer to this question.

In summary then, the existence of corrective taxation (especially as a substitute for legal rules) is no objection to the argument that legal rules, in addition to income taxes, should be used to redistribute income.

accompanying text. Briefly, without perfect information on individuals' income-earning potential, a redistributive lump-sum tax is considered unrealistic. Nevertheless, several tax law scholars have made the argument for the plausibility of endowment taxation. For a critique of this position and an overview of the relevant literature, see Ilan Benshalom \& Kendra Stead, Values and (Market) Valuations: A Critique of the Endowment Tax Consensus, 104 Nw. U. L. REV. 1511 (2010).

259 Mirrlees, supra note 187, at 175 (“[T]he natural, and one would suppose most reliable, indicator of [a person's] income earning potential is his income.").

260 Indeed, to link this back to previous discussions, credit markets are a good example of where corrective taxes can increase efficiency and reduce inequality. See supra Parts II.C.3 and IV.D; see also Bowles \& Ginitis, supra note 152, at 3-71; Hoff, supra note 10.

261 See, e.g., Louis Kaplow \& Steven Shavell, On the Superiority of Corrective Taxes to Quantity Regulation, 4 AM. L. Econ. REv. 1 (2002) (arguing that if the government can impose a nonlinear tax equal to the schedule of harm or can adjust the tax rate upon learning that it diverges from marginal harm, then corrective taxes are superior to quantity regulation); Edward L. Glaeser \& Andrei Shleifer, A Reason for Quantity Regulation, 91 Am. Econ. Rev. 431 (2001) (arguing that quantity regulation is frequently superior to corrective taxes because of lower enforcement costs). 


\section{Distribution Policy in a Second-Best World}

The purpose of this concluding Part is to situate my argument within a broader economics literature. It is well recognized that in a world of perfect markets, taxation is the best way to achieve any distributive objectives society or policymakers might have. The double-distortion argument can be read as a way to justify a similar conclusion in a world of imperfect markets. But once we have admitted to a world of market imperfections, this also justifies the use of legal rules both to enhance efficiency and reduce inequality. Market failures will create efficiency losses, and there is no reason why these losses may not also increase inequality, as all of the previous examples have demonstrated. Once this is conceded, then there is always a role for legal rules to enhance both efficiency and equity.

\section{A. The Fundamental Theorems of Welfare Economics}

One can read Kaplow and Shavell's argument as a way of endorsing what is called the "second fundamental theory of welfare economics" for a world of imperfect competition. To understand the second fundamental theorem, we briefly introduce the first.

The first fundamental theorem of welfare economics states that a perfectly competitive economy achieves a Pareto efficient allocation of resources. ${ }^{262}$ In other words, in a perfectly competitive economy we have reached the Pareto frontier, all Pareto improvements have been exhausted, and it is not possible to make anyone better off without also making someone worse off. ${ }^{263}$

In contrast to the first fundamental theorem of welfare economics, the second theorem states that any Pareto efficient allocation of resources within a perfectly competitive economy can be achieved with lump sum taxes. ${ }^{264}$ Since it is possible for some Pareto efficient allocations to be highly, even perfectly, equal, the idea is that one can obtain any desired distribution of income solely through the tax system without sacrificing economic efficiency. ${ }^{265}$ The main attraction is that there is no need to reorganize the economy to achieve distributive objectives. ${ }^{266}$ The economy achieves an optimal level of output in a decentralized fashion, while

262 Stiglitz, supra note 255 , at 259.

263 Id.

264 Id.

265 HindRiks \& MYLES, supra note 50, at 424.

$266 I d$. (noting that after consumers are assigned lump-sum transfers, they will "then trade, and the chosen equilibrium will emerge as the competitive equilibrium. This is the process of decentralization") (emphasis in original). 
the tax system is the sole instrument necessary for influencing the distribution of economic rewards. ${ }^{267}$

Critical to the second fundamental theorem is the idea of lump sum taxes. Intuitively, a lump sum tax is one that has no distortionary impact on economic behavior. ${ }^{268}$ This is certainly a necessary feature of the tax system if one wants to achieve a desired distribution of resources without causing any loss to economic output. A more formal, but slightly less intuitive definition says that lump sum taxes are those where the consumer cannot vary the amount of tax paid by changing her behavior. ${ }^{269}$ Under this definition, every tax instrument fails to be lump sum. For instance, one can change the amount of income tax paid by working less. A person can also change the amount of commodity taxes paid by changing saving and consumption patterns. Estate taxes can be avoided by making inter vivos transfers. ${ }^{270}$ In the late 1980s, the United Kingdom implemented a poll tax, which came close to a lump sum tax because it levied the same amount on every individual. Yet even in this case, individuals could vary the amount of tax they paid by moving, not making any official declaration about the new address, and therefore failing to appear on local tax registers. ${ }^{271}$ Even if poll taxes did not influence behavior, they would not be optimal lump sum taxes. Since the appeal of the second fundamental theorem is that any desired distribution of income can be achieved, optimal lump sum taxes will in general redistribute and therefore necessarily vary across persons of different consumption tastes and production abilities. ${ }^{272}$ In principle, one could achieve optimal lump sum taxation if one had knowledge about individuals' consumer preferences and economic endowments (e.g., their ability or productivity). ${ }^{273}$ But because this is private information for each indi-

267 Id. ("In achieving the decentralization of the allocation, only two policy tools are employed: the encouragement of competition and a set of lump-sum taxes to ensure that each consumer has the required income.").

268 HindRIKS \& MYLES, supra note 50, at 428.

269 "In order for a tax to be lump sum, the consumer on whom the tax is levied must not be able to affect the size of the tax by changing their behavior." HindRIKS \& MYLES, supra note 50 , at 428 .

270 Id. (discussing how each of these examples - income tax, commodity tax, and estate tax-fail to act like lump-sum taxes).

271 Id. (discussing how the UK Poll Tax came close to working, but still failed to work, as a lump-sum tax).

272 Id. ("[B]ecause the role of lump-sum taxes [in the Second Theorem] is fundamentally redistributive, . . . the taxes will be highly differentiated across consumers. Since even uniform lump-sum taxes are implemented with difficulty, the use of differentiated taxes presents even greater problems.").

273 Id. at 428-29 (describing how the calculation of the optimal lump-sum transfers requires knowledge of both preferences and endowments). 
vidual, and cannot be known with certainty by a policy maker, lump sum taxation is thought to be impossible in practice. ${ }^{274}$

The impossibility of lump sum taxes then leads to the conclusion that taxes will always distort economic behavior. In any case, the policy implications of the second fundamental theorem and its relationship to the double-distortion argument should now be clear. Under both conceptions, the legal system need not be used to address distributional issues. Rather, the legal system should merely serve to support the efficient production of goods and services. Distributional objectives should be left entirely to the tax system.

One can then interpret the double-distortion argument as a version of the second fundamental theorem of welfare economics for a world of imperfect competition. In making their argument, Kaplow and Shavell implicitly acknowledge the second fundamental theorem of welfare economics. As they explain, criticism of the position that legal rules should be evaluated solely with regard to their efficiency effects "would be moot if the income tax system-understood here to include possible transfer payments to the poor-could be used freely to achieve any desired distribution of income." 275 And as we saw, the second fundamental theorem states that any desired Pareto efficient allocation of resources, including more equal distributions, can be achieved with lump sum taxation. Yet, lump sum taxation is infeasible and therefore "income taxes and transfer payments distort incentives to work, limiting the degree to which it is socially desirable to employ the income tax system to redistribute income."276

The Kaplow-Shavell argument is therefore distinct from the second fundamental theorem. They acknowledge that in general lump sum taxation cannot be achieved and taxation is distortionary. At the same time, the second theorem clearly animates their argument. Like the second theorem, they share the conviction that the functioning of the economy, including the legal system that supports and makes it possible, should have efficiency as its sole objective. The tax system, and not the legal system, should address distributive concerns.

\section{B. The General Theory of the Second Best}

If one can interpret the double-distortion argument as a version of the second fundamental theorem of welfare economics for a world of imperfect competition, then one can also situate my argument within a different general conclusion found in welfare economics. This idea is

$274 I d$. at 429 ("The fundamental difficulty is that these economic characteristics, preferences and endowments, are private information.").

275 Kaplow \& Shavell, supra note 261, at 667.

276 Id. 
called the general theory of the second best. The term "second best" is in contrast to the term "first best," a situation where all of the conditions for a competitive economic equilibrium are satisfied, and thus a Pareto efficient allocation of resources exists. ${ }^{277}$ The theory of the second best says that if one of the conditions for Pareto efficiency fails to be satisfied, then even if the other Pareto efficient conditions are attainable, they are no longer desirable. ${ }^{278}$ To put it more sharply, if one of the conditions for Pareto efficiency fails, then a second-best welfare maximizing allocation can be achieved only by departing from the other Pareto efficiency conditions. 279

The theory of the second best grew out of the literature on trade and tariffs. For one example, among others, it was shown that "the adoption of a free trade policy by one country, in a multi-country tariff ridden world, may actually lower the real income of that country and of the world." 280 Thus, the existence of tariffs violates one of the Pareto efficiency conditions. But the lowering of trade barriers by one country, instead of leading to an incremental improvement in welfare, actually lowers it. ${ }^{281}$ Another example comes from the analysis of a production

277 R. G. Lipsey \& Kelvin Lancaster, The General Theory of Second Best, 24 Rev. Econ. STUD. 11 (1956) ("It is well known that the attainment of a Paretian optimum requires the simultaneous fulfillment of all the optimum conditions.”).

278 Id. ("The general theorem for the second best optimum states that if there is introduced into a general equilibrium system a constraint which prevents the attainment of one of the Paretian conditions, the other Paretian conditions, although still attainable, are, in general, no longer desirable.").

279 Id. ("In other words, given that one of the Paretian optimum conditions cannot be fulfilled, then an optimum situation can be achieved only by departing from all the other Paretian conditions.").

$280 \mathrm{Id}$. at 16.

281 In the trade example, one might argue that it would better if all countries eliminated trade barriers, thus removing all of the barriers to Pareto efficiency. Yet, some violations of the Pareto-optimality conditions may not be possible to surmount even in principle. These obstacles to Pareto efficiency can be summarized in three broad categories: externalities, market power, and asymmetry of information. See generally MAS-COLELL ET AL., supra note 86, at 308-09. The first is externalities. $I d$. at 308, 350-82. If a firm does not bear all of the costs of its activities and uses a production process that imposes negative externalities on others-e.g., pollution - there will be too much of the good produced, lowering welfare. This situation is not Pareto efficient, since some could be made better off without making others worse off-if the citizens pay the firm to stop polluting. Alternatively, if there is a positive externality, producers do not enjoy all of the benefits from making the good, and too little of the good will be produced. The second category is market power. $I d$. at 308-09, 383-435. A competitive economy requires that all consumers and producers act as price takers, and that their behavior cannot affect prices. Essentially, demand or supply functions are infinitely elastic at going market prices. Yet if, for example, there are only few agents on one side of the market (either a few producers or a few buyers), then this condition will not be satisfied. These agents will possess market power, defined as the ability to profitably set prices away from their competitive levels. The third category is information imperfections, both hidden information (adverse selection) or hidden action (moral hazard). Id. at 309, 436-513. For instance, a firm that hires a worker will often know less about the ability of the worker than the worker herself. Classically, in a used-car market, the seller will have better information about the quality of the car 
problem. Typically, profit maximization requires, from the familiar textbook condition, that marginal productivity equal marginal cost. But suppose one of the inputs of a multi-input production process used by a firm is fixed at some minimum amount, above that which the firm would prefer to employ to maximize profits. Then the second-best maximization of profits requires not only that marginal productivity not equal marginal cost for this particular input, but that marginal productivity not equal marginal cost for all of the other inputs as well. ${ }^{282}$

The lessons of the theory of the second best can be easily applied to the debate between the choice of taxes and legal rules to redistribute income. ${ }^{283}$ Most generally, because the optimal tax policy will be distortionary, and lead individuals away from first-best behavior, it will not be desirable to choose otherwise Pareto efficient legal rules. Although the general theory of the second-best says little about what these legal rules will look like in each circumstance, we can be sure of this conclusion in general.

More specifically, the minimum wage case described in Part II.C.2 offers a good example of the theory of the second best in action. As we saw there, in a perfectly competitive labor market, the Pareto efficient allocation of labor requires equating marginal benefits and costs: the marginal productivity of labor should be equal to the wage. However, once a (distortionary) tax scheme is in place, setting wages equal to the marginal product of labor becomes inefficient. A work subsidy encourages too much labor. The social-welfare maximizing solution then is to implement a minimum wage higher than the marginal productivity of

than the prospective buyer. Finally, even if an employer knows the ability of an agent, she may not always be able to perfectly monitor the effort she exerts in her duties. In all of these cases, market equilibria frequently fail to be Pareto efficient. The main conclusion here is that if departures from Pareto efficiency are pervasive and obstin ate, then the lessons of the theory of the second best need to be constantly kept at the forefront.

282 One interpretation of the theory of the second best offered by economists and others is that if there are departures from perfect competition, economic theory has nothing to say. But this conclusion is incorrect. "Economic theory can tell us under what circumstances two small distortions are preferable to one large one; when it is better to have inefficiencies in both consumption and production; and when it is better not to have inefficiencies in production." Joseph E. Stiglitz, Economics of the Public Sector 551 (3rd ed. 2000). The real lesson of the second best is not that economic theory is useless. Rather, it tells us that we cannot "blindly apply" first-best policy advice as if we are in a second-best world. Id. Finding the second-best solution may be difficult, because when one Pareto condition fails, nothing in general can be said about the direction or magnitude of the departure from the secondary optimum conditions that will implement the second best. Lipsey \& Lancaster, supra note 277, at 12 ("It is important to note that in general, nothing can be said about the direction or the magnitude of the secondary departures from optimum conditions made necessary by the original non-fulfillment of one condition."). This means that figuring out the best policy to take requires work-which is unfortunately often the case for any policy or legal analyst.

283 For an even more extensive discussion applying the general theory of the second best to the double-distortion argument, see generally Deconstructing, supra note 5 . 
labor. In the absence of a distortionary tax (and assuming perfectly competitive labor markets), the optimal solution is no regulation of the labor market. Once a distortionary tax is introduced, however, this is no longer the case.

In summary, Kaplow and Shavell's argument can be seen as a reiteration of the second fundamental theorem of welfare economics. But, once imperfect competition is introduced, endorsing legal rules that implement the putatively efficient allocation may not be welfare maximizing. In particular, the same information problems that make taxation distortionary may also create inefficiencies that increase inequality. In this context, legal rules have a clear scope to both address the inefficiency and reduce inequality.

\section{Conclusion}

An influential policy position found throughout various academic disciplines and across the political spectrum is that only the tax system, and not the legal system, should be used to redistribute income. Within law and economics, Kaplow and Shavell's double-distortion argument supports this view. The double-distortion argument states that redistributive legal rules only add to the distortions already created by the tax system. Everyone-the poor included - could therefore be made better off by adopting an efficient, non-redistributive legal rule and increasing transfers to the poor and reducing taxes.

This Article has challenged the double-distortion argument, with two main contentions. First, there is no compelling reason why redistributive legal rules will also be distortionary. Several examples demonstrate that rules that reduce inequality also increase efficiency. In these cases, legal rules can redistribute income more efficiently than taxes. Second, even if redistributive legal rules reduce efficiency, this does not automatically make taxation a superior option. Indeed, the set of more efficient redistributive legal rules typically will be larger when either inequality or our normative distaste for it becomes larger.

The main conclusion is that taxation should not be the exclusive tool used to redistribute income. Rather, the optimal-welfare maximizing - set of policies will use a mix of both legal rules and taxes to redistribute income. How much and in what proportion each should be used is not a question that can be answered in the abstract. One attraction of the double-distortion argument is its generality. Essentially the argument resolves this choice for us a priori by claiming that taxation will always be more efficient than legal rules. Unfortunately, as this Article has demonstrated, we do not have that luxury. Because legal rules can sometimes be both more efficient and redistributive, we must consider each situation, case-by-case, to determine whether legal rules should or should not be 
used to redistribute income. The double-distortion argument does not save us from the hard work of comparative and institutional analysis.

Figure 1: ECONOMIC EFFICIENCY

$U_{2}$

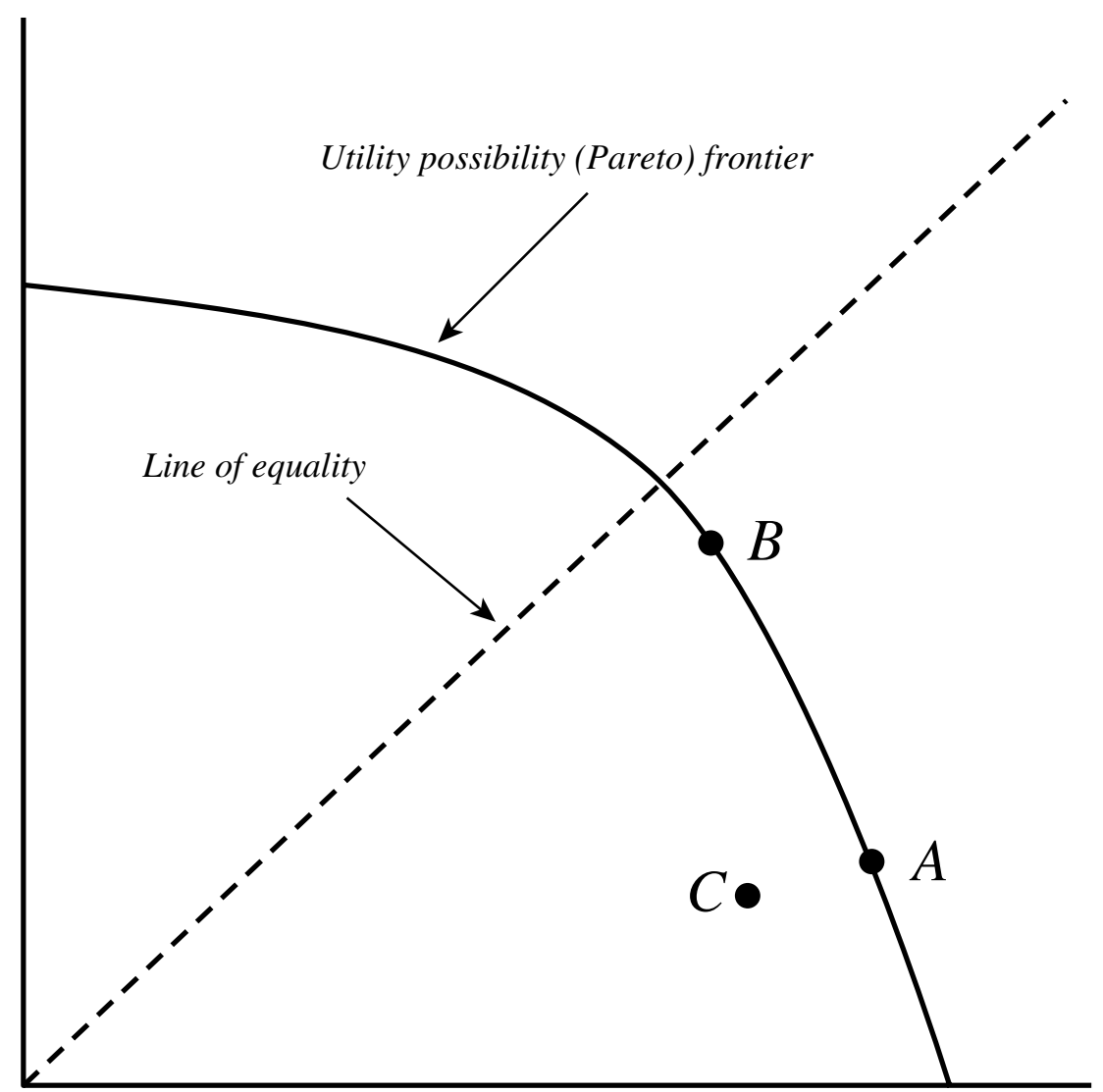

$U_{1}$ 
Figure 2: Social Welfare

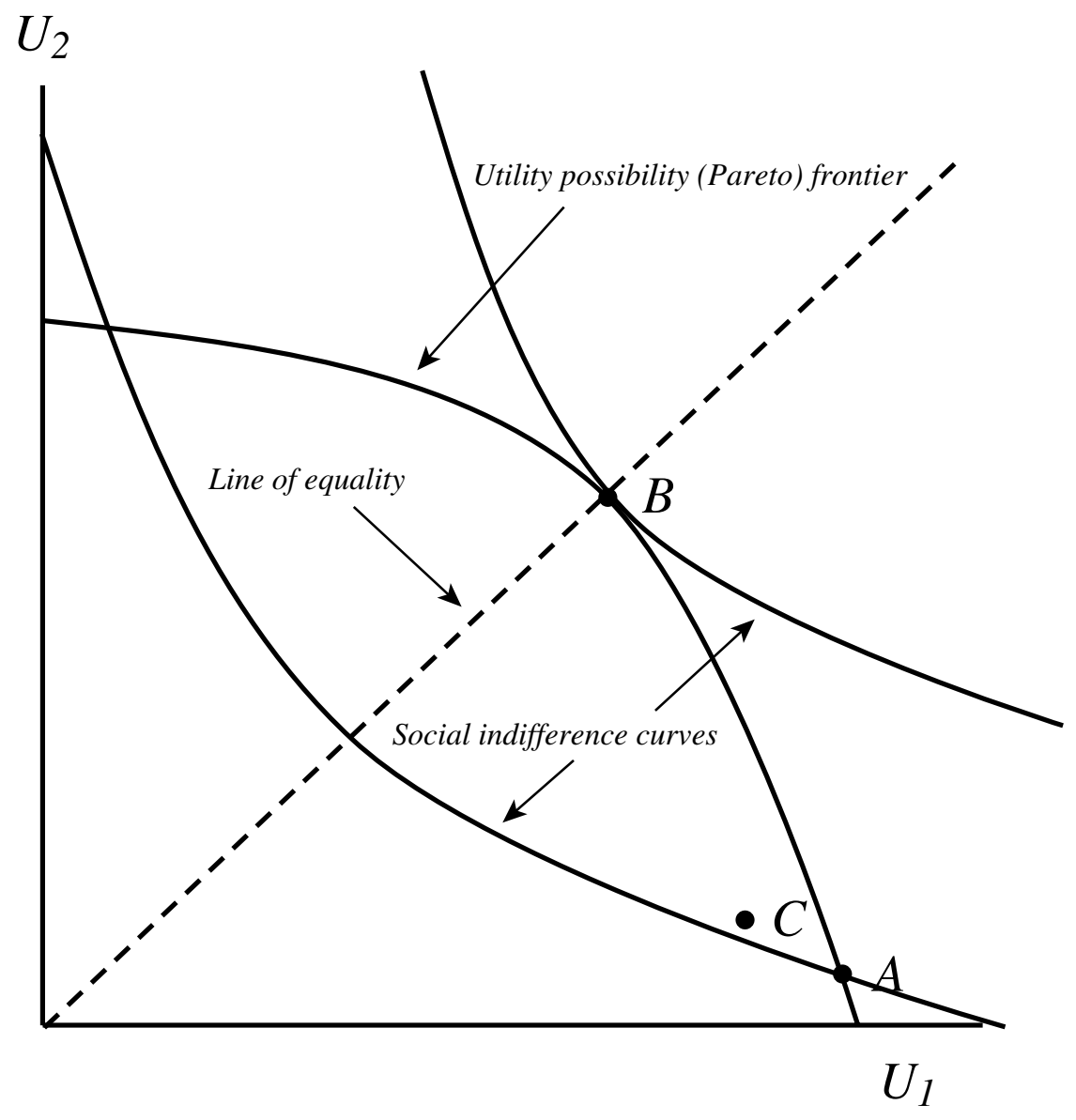


Figure 3: LoRenz Dominance

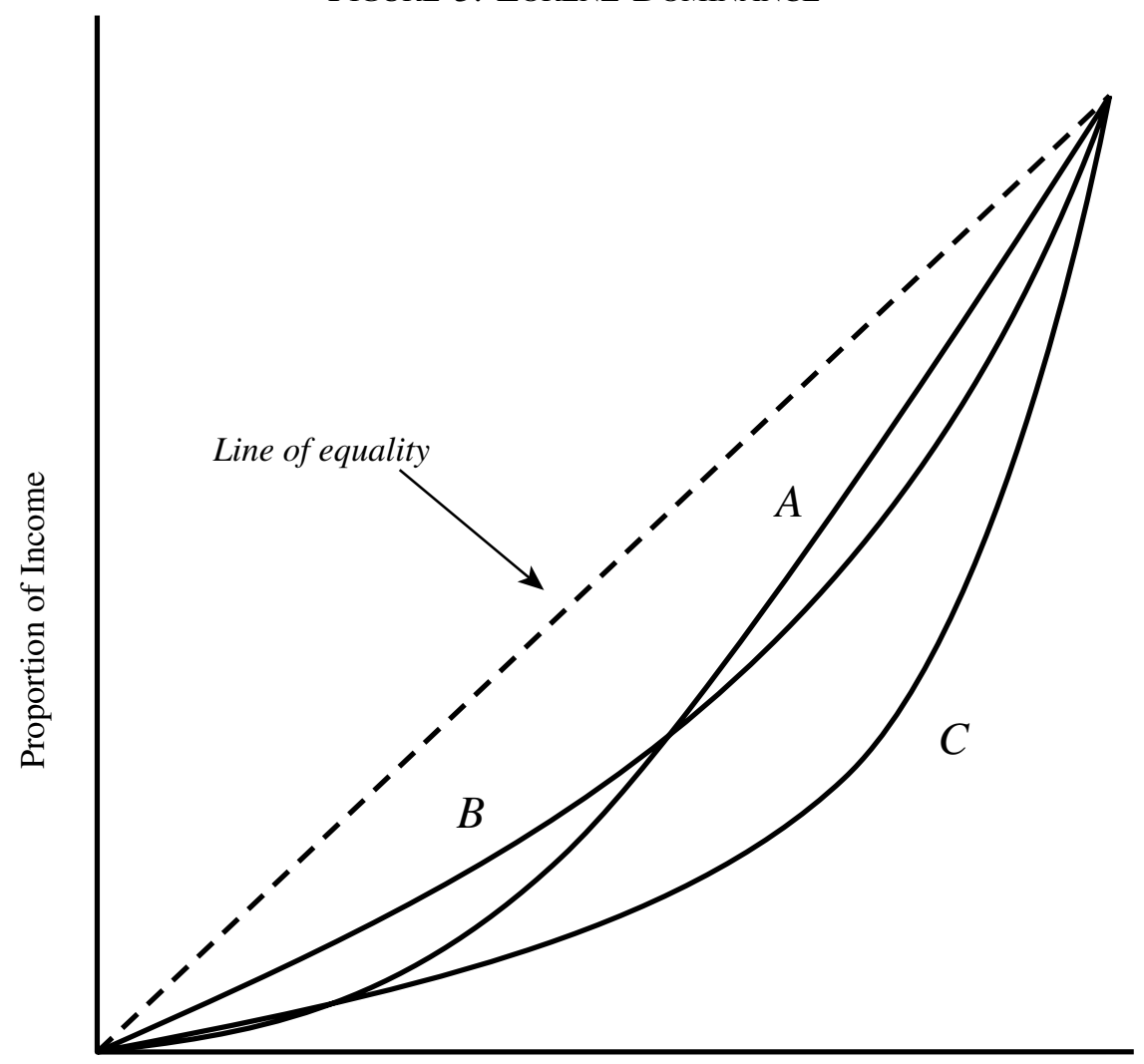

Proportion of Population 
Figure 4: Efficient Legal Redistribution

$U_{2}$

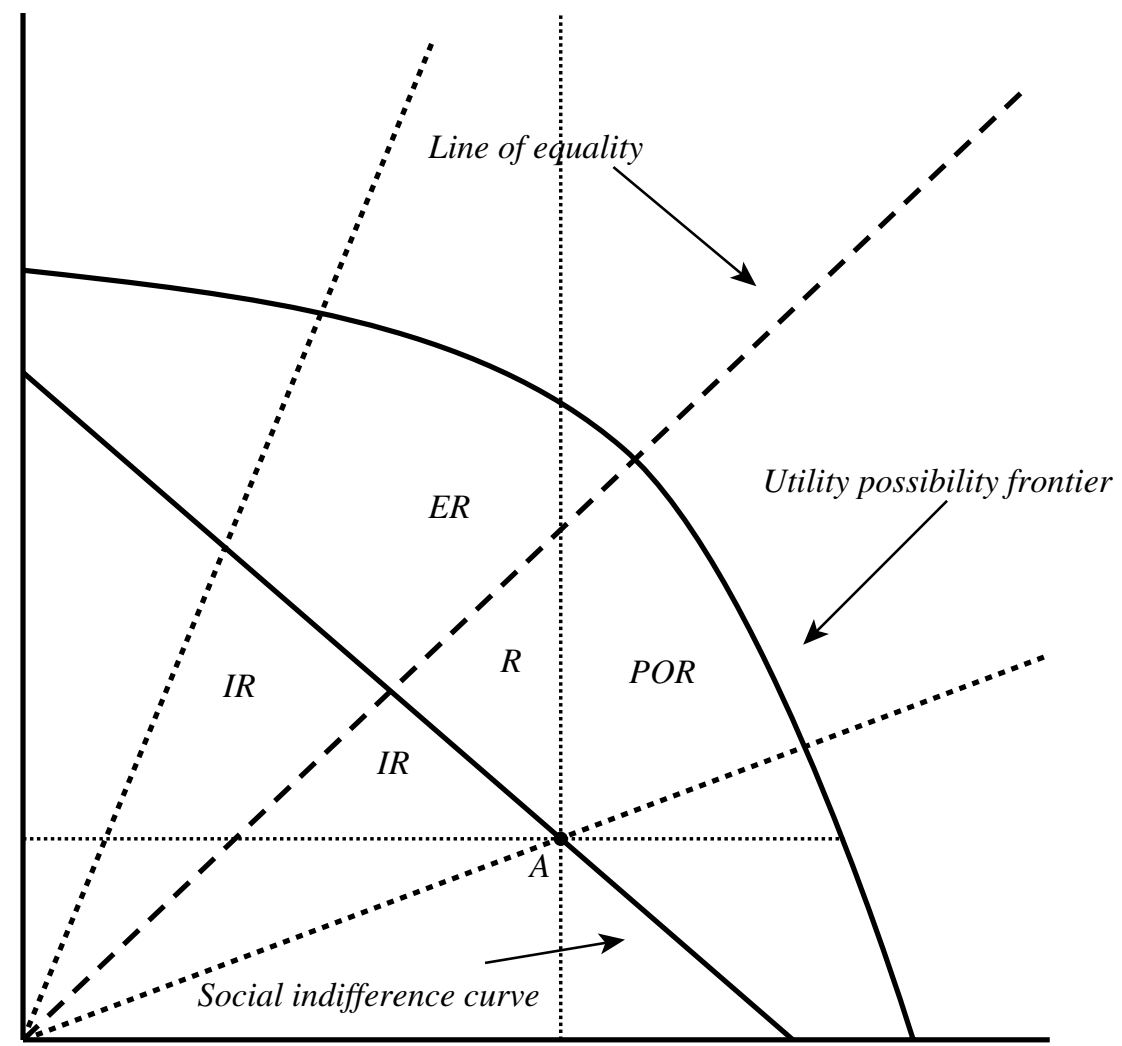

$U_{1}$ 
Figure 5: Inefficient Legal Redistribution and Distributional JUDGMENTS

$U_{2}$

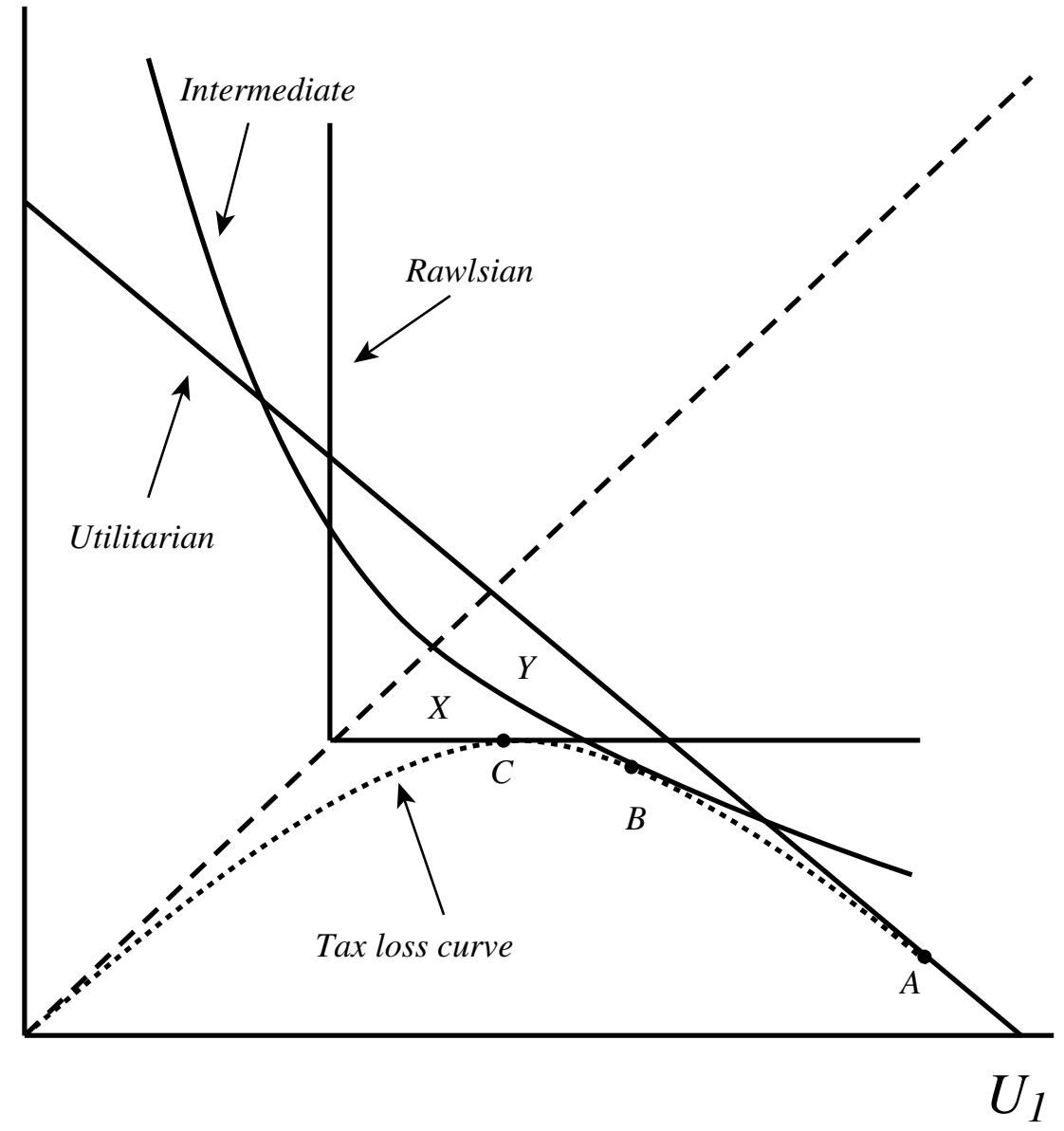


Figure 6: InefFicient Legal Redistribution and Inequality $U_{2}$

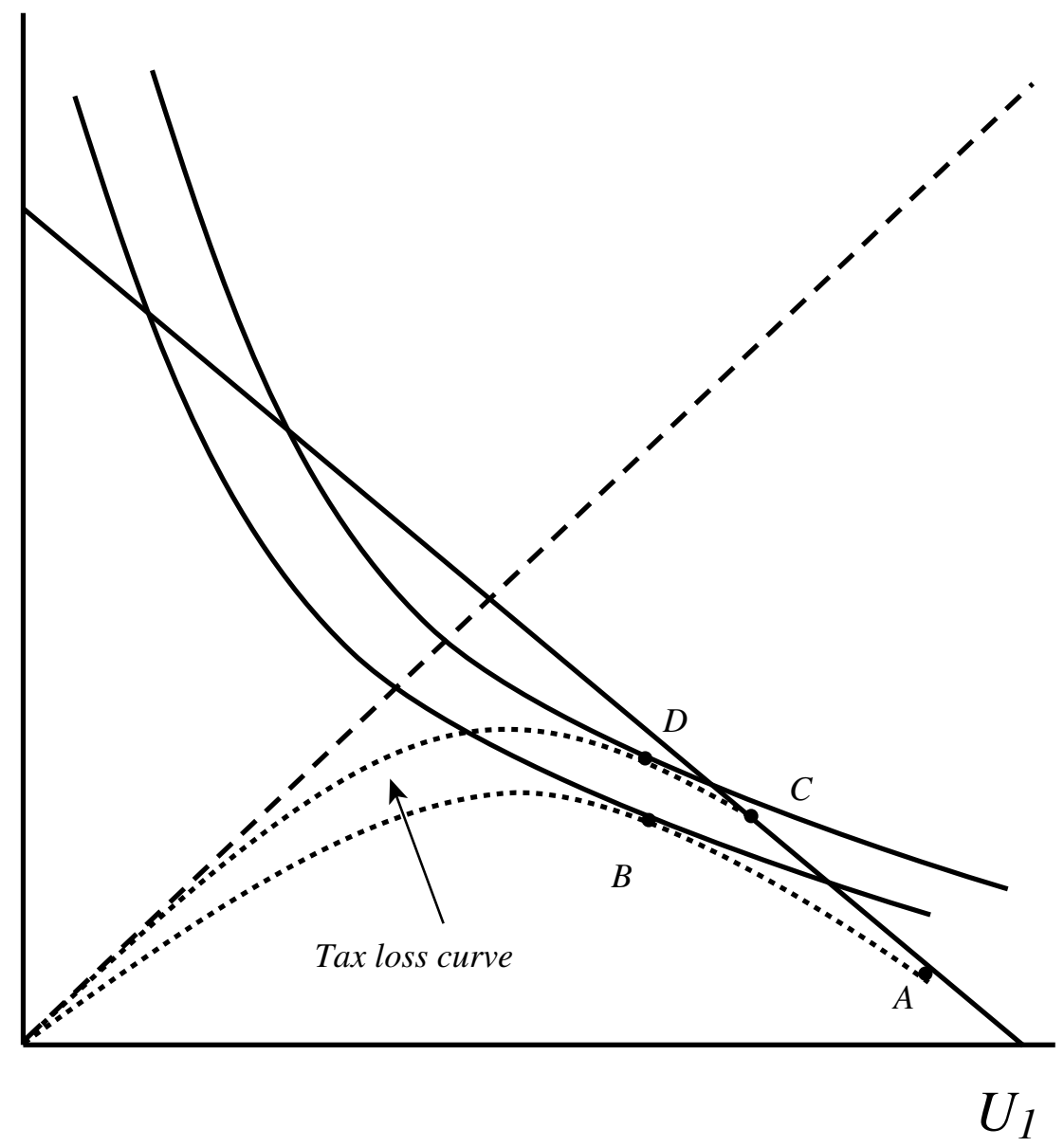


